\title{
PHYLOGENY OF THE TRAF/MATH DOMAIN
}

\author{
Juan M. Zapata ${ }^{1,2,3}$, Vanesa Martínez-García ${ }^{1,2}$ and Sophie Lefebvre ${ }^{1}$ \\ ${ }^{1}$ Burnham Institute for Medical Research, 10901 N. Torrey Pines Road, La Jolla, CA \\ 92037 and ${ }^{2}$ Centro de Biología Molecular Severo Ochoa, Universidad Autónoma de \\ Madrid, Cantoblanco, Madrid 28012.
}

\section{${ }^{3}$ Address correspondence to: jzapata@burnham.org}

This chapter is dedicated to the memory of José Zapata Ruiz, my beloved father and strongest supporter.

Keywords:

TRAF

MATH domain

UBP

BTB domain

POZ domain

TRIM

Meprin

Siah

TNFR

TLR 


\section{Abstract}

The TNF-Receptor Associated Factor (TRAF) domain (TD), also known as the meprin and TRAF-C homology (MATH) domain is a fold of seven anti-parallel $\beta$-helices that participates in protein-protein interactions. This fold is broadly represented among eukaryotes, where it is found associated with a discrete set of protein-domains. Virtually all protein families encompassing a TRAF/MATH domain seem to be involved in the regulation of protein processing and ubiquitination, strongly suggesting a parallel evolution of the TRAF/MATH domain and certain proteolysis pathways in eukaryotes.

The restricted number of living organisms for which we have information of their genetic and protein make-up limits the scope and analysis of the MATH domain in evolution. However, the available information allows us to get a glimpse on the origins, distribution and evolution of the TRAF/MATH domain, which will be overviewed in this chapter.

\section{Introduction.}

TNF-Receptor Associated Factors are a family of proteins that were initially identified for their capability of interacting with and regulating different members of the TNFR family ${ }^{1-4}$. TRAFs are characterized by a C-terminal region encompassing about 180 aminoacids, forming a 7-8 antiparallel $\beta$-sheets fold (TRAF-C domain) (Fig.1), which is preceded by a coiled coil (TRAF-N)

domain ${ }^{1}$. Meprins, a family of extracellular metalloproteases, also contain a C-terminal domain with high sequence homology to the TRAF-C domain ${ }^{5}$ which is predicted to form a similar anti-parallel $\beta$-sheets fold ${ }^{6}$. Therefore, the TRAF-C domain is also known as the meprin and TRAF Homology (MATH) domain.

MATH domain (MATHd) encompassing proteins are found associated to a discrete set of other protein domains, including peptidases, filamin and RluA domains, broad-complex, tramtrack and bric a brac (BTB) domain, tripartite motif (TRIM), astacin domain and RING and Zinc finger domains (Fig. 2).

Remarkably, all different MATHd encompassing protein subfamilies seems to have a role in the regulation of protein processing. In this regard, the members of the MATHd ubiquitin proteases (UBPs) and meprins have intrinsic protease activity, while TRAF, TRIM/MATHd and BTB/MATHd proteins, as well as the MATHd structural homolog SIAH, appear to function as E3 ubiquitin ligases (Fig. 3). 
The MATHd is found in a variety of proteins in humans ${ }^{7}$, and blast searches using as bait the MATHd of TRAF2 readily produced hundreds of hits widely distributed among eukaryota. Thus, MATHd encompassing proteins are currently found in 72 species of eukaryotes and 3 iridoviruses (Fig. 4), but this number will grow as we gather more information of the genomes of new organisms. Interestingly, genes encoding MATHd proteins have been found in lower eukaryotes such as protozoa and unicellular fungi, but not in any of the prokaryota and archaea species for which the full genome sequence is known, suggesting that the MATHd might have appeared early in the evolution of eukaryotes.

Next we will overview the different types of MATHd encompassing proteins according to the other protein domains they are found associated to.

\section{Ubiquitin Proteases (UBPs)}

Ubiquitin proteases (UBPs), also known as deubiquitinating enzymes, are a family of cysteine proteases involved in the removal of ubiquitin from proteins. There are five UBPs subclasses, each of them encompassing a different type of deubiquitinase domain: 1) ubiquitin specific proteases (USP), 2) ubiquitin C-terminal hydrolases (UCH), 3) ovarian tumor proteases (OTU), 4) Machado-Joseph disease protein domain proteases (MJDP) and JAMM motif proteases ${ }^{8}$,

9 . Some UBPs are found associated to the proteasome where they remove the poly-ubiquitin chains from the proteins that are being degraded by the proteasome, allowing for ubiquitin recycling. In contrast, other UBPs remove the poly-ubiquitin chains from proteins to prevent their degradation by the proteasome ${ }^{8}$. This is the case of ubiquitin specific proteases (USP), which account for the majority of UBPs found in mammalian genomes. USPs seem to counterbalance E3 ubiquitin ligases by removing ubiquitins from proteins, thus preventing their degradation, Indeed, a coevolution of both types of enzymes has been suggested ${ }^{10}$.

MATHd encompassing UBPs are found in unicellular organisms, such as Mycetozoa (Dictyostelium), Alveolata (Cryptosporidium) and Fungi of the Ascomycota and Basidiomycota phyla. They are also found in plants (Arabidopsis, Oryza) and in Metazoa (Fig. 4). Interestingly, there is a remarkable conservation among organisms of both, the size of the protein, which contains over 1000 amino-acids, and its domain organization, with the MATHd located at the N-terminus of the protein followed by the ubiquitin protease domain. Theoretical phylogenetic analysis based on 
the homologies of all MATHd protein sequences available showed that all UBP/MATHd proteins form a distinctive cluster, and that fungi, metazoa and plant UBP/MATHd proteins were distributed in three well defined subgroups (Fig. 5). One exception corresponds to the UBP/MATHds from Cryptosporidium (Alveolata), which according to the protein sequence comparison, contain the most divergent MATHds of all analyzed (Fig 6, bottom).

The analysis of the MATHd sequences shows a unique conservation among UBPs of the residues ExDWGF in the $\beta$-sheet 7 (Fig. 6), which correspond to residues ${ }^{162}{ }^{E N D W G F}{ }^{167}$ of human USP7 ${ }^{11}$. Furthermore, in all cases the protease domain is a peptidase C19C (cd02659), a subgroup of the peptidase 19 group of ubiquitin carboxyl-terminal hydrolases that removes ubiquitin molecules from polyubiquinated peptides by hydrolyzing bonds involving the carboxyl group of the C-terminal Gly residue of ubiquitin. It is also noteworthy that 35 out of 37 species included in our UBP/MATHd analysis contain only one UBP/MATHd. Only two species (O. sativa and C. elegans) contain two different UBP/MATHd genes. Altogether, these results illustrate the strong conservation of UBP/MATHd genes in eukaryotes, suggesting that UBP/MATHd proteins in different species might be orthologs.

The only UBP/MATHd protein found in the human and mouse genome is USP7. The crystal structure of the MATHd of USP7 has been recently solved ${ }^{11}$. It is a fold of eight anti-parallel $\beta$ sheets very similar to the TRAF-C domain of TRAFs (Fig. 1). The USP7's MATHd has been implicated in substrate recognition. Indeed, USP7 was originally identified by its interaction with ICP0 protein from herpes simplex virus ${ }^{12}$. USP7 also interacts with p53 and Mdm2 ${ }^{13}$, and EpsteinBarr virus nuclear antigen 1 (EBNA1) protein ${ }^{11}$.

Interestingly, USP7's MATHd accommodate the MATHd-binding-motifs of p53, Mdm2 and EBNA1 in a shallow surface groove in the middle of the $\beta$-sandwich which is much alike the TNFRpeptide binding crevice located across the edge of the $\beta$-strands of TRAFs ${ }^{14-17}$. However, the mode of peptide binding and the adopted conformation of the bound peptide differ significantly from previously observed TRAF-peptide interactions ${ }^{11,13,18}$. Most interestingly, the key aminoacids in USP7's MATHd interacting with all these different substrates are ${ }^{164} \mathrm{DWGF}^{167}$, which shape the peptide-binding pocket and, as indicated above, are distinctively conserved among UBPs. Other aminoacids participating in interaction account for the differences in affinity of the different 
substrates, but interactions with the DWGF, in particular with Trp165, are critical for the specificity of the binding ${ }^{11,13,18}$.

Structural and competition data support that Mdm2 has a higher affinity for binding USP7 than has $\mathrm{p} 53^{13,18}$. Mdm2 is a ubiquitin ligase that regulates p53 activity, traffic and degradation ${ }^{19}$. It has been shown that USP7 might stabilize Mdm2 and promote p53 degradation ${ }^{20,}{ }^{21}$. However, functional ${ }^{22}$ and structural ${ }^{13,18}$ data shows that USP7 also interacts with and deubiquitinates p53, thus preventing its degradation by the proteasome. Therefore, USP7 appears to play multiple roles in regulating the p53-Mdm2 pathway.

Interestingly, EBNA1 seems to have the higher affinity for USP7 of all known substrates, and functional studies have shown that interaction of EBNA1 with USP7 protects cells from apoptotic insults by preventing USP7-mediated deubiquitination of p53 in vivo, resulting in p53 degradation. Indeed, it has been proposed that this is the mechanism by which EBNA1 contributes to the survival of Epstein-Barr virus-infected cells ${ }^{11}$. However, Mdm2 activity would also be affected by EBNA1 association to USP7, which as a result might prevent p53 degradation. Additional work is necessary to clarify the role of USP7 and their substrates in the control of p53-mediated activities.

It is noteworthy that $\mathrm{p} 53, \mathrm{Mdm} 2$ and related proteins are only found in vertebrates. In addition, herpes viruses only infect vertebrates. It seems likely that Epstein Barr virus EBNA1 and herpes simplex virus ICP0 have co-evolved along with p53 and Mdm2 to efficiently out-compete these two proteins from binding USP7, thus efficiently hick-jacking p53-mediated pathways. Consequently, none of these proteins can be the original substrate(s) for USP7 and its putative orthologs in lower eukaryotes and plants. Considering the high conservation of MATHd/UBPs in evolution, it should be expected that this still unidentified primordial substrate(s) should be essential for all these organisms and should also have remained well conserved during evolution.

There is an additional set of MATHd sequences from Arabidopsis thaliana and Dictyostelium discoideum sharing a high homology with UBP/MATHd but lacking the ubiquitin protease domain. They still have the ExDWGF motif or close variations of it, further suggesting that they arose from a common ancestor (Fig 6). 


\section{RluA and Filament domains}

MATHd encompassing proteins that also contain a pseudo-uridine synthase Rlu domain are found in Alveolata. One of these putative proteins is encoded by the genome of Cryptosporidium parvum (CAD98470), and the other one is found in Plasmodium falciparum (NP703459). The Rlu domain is involved in the conversion of uracil bases to pseudo-uridine ${ }^{23}$.

The filament domain represents the N-terminal head region of intermediate filaments that bind DNA ${ }^{24}$ and is found associated to MATHd in one putative protein from Arabidopsis thaliana (AAD23659). The function of this MATHd encompassing protein in Arabidopsis is not known.

\section{BTB/POZ domains}

The BTB (for broad-complex, tramtrack and bric a brac) domain, also know as POZ (for Pox virus and Zinc finger) domain is an evolutionarily conserved domain broadly distributed in eukaryotes ${ }^{25,26}$. The crystal structure of the POZ domain of the human promyelomonocytic leukemia zinc finger (PLZF) protein consists of a cluster of alpha-helices flanked by short betasheets at both the top and bottom of the molecule, that tightly homodimerizes by intertwining both domains producing an extensive hydrophobic interface ${ }^{26,27}$.

Proteins encompassing a MATH domain and a BTB/POZ domain are broadly represented among eukaryotes (Fig. 4). Thus, proteins of this group are found in lower eukaryotes, such as Trypanosomatidae (Euglenozoa), and Coccidia (Alveolata), plants (Viridiplantae) including both eudicotyledons and monocotyledons (liliopsidae), and in metazoa. However, MATH/BTB proteins have not yet been found in fungi. The vast majority of BTB/MATHd proteins have an N-terminal MATHd and a C-terminal BTB domain, but there are also examples of genes encoding proteins with a N-terminal BTB domain and a C-terminal MATHd. Also, some proteins contain MATHd/BTB domains in tandem (Fig. 2).

A large cohort of putative genes encoding MATH/BTB proteins (about 49) are found in Caenorhabditis elegans. These genes would encode proteins with an N-terminal MATHd and a Cterminal BTB/POZ domain. One of these proteins, the maternal effect lethal (MEL)-26, has been shown to regulate the transition from meiotic to mitotic chromosome segregation ${ }^{28}$. MEL-26 is part of the CULLIN (CUL)-3 ubiquitin ligase complex ${ }^{29-31}$. CUL-3 is an E2 ubiquitin conjugating enzyme. MEL-26 interacts with CUL-3 through its $\mathrm{BTB} / \mathrm{POZ}$ domain and acts as an E3 ubiquitin 
ligase, which is required for ubiquitination and degradation of the meiosis defective (MEI)-1 protein ${ }^{29,30}$. Three other MATH/BTB proteins that interact with CUL-3 were identified in C. elegans ${ }^{29}$

SPOP (also known as TEF2) ${ }^{7,32}$ and its close relative TEF4 ${ }^{33}$ deserve special mention among the MATHd/BTB proteins. These two genes are strikingly conserved in metazoans, including nematoda, arthropoda and chordata (Fig. 7). SPOP (TEF2) has been shown to form an E3 ubiquitin ligase complex with CUL-3. SPOP (TEF2) regulates the ubiquitination and subsequent proteasomemediated degradation of several proteins, including the polycomb group protein BMI1, which regulates survival and senescence of stem cells and cancer cells ${ }^{34-36}$, the variant histone MACROH2A, which is required for the silencing of one of the two $\mathrm{X}$ chromosomes in $\mathrm{XX}$ female somatic cells ${ }^{37}$ and DAXX, a multifunctional protein involved in the regulation of cell death $\left({ }^{38}\right.$ and references therein). These examples further extend the role of MATHd/BTB proteins as E3 ubiquitin ligases. It is worth noting, that the MATHds of SPOP and relatives are more conserved than their corresponding BTB domains. For instance, the percentage of identity between the BTB domains of C.elegans and homo sapiens is $56 \%$, while the percentage of identity of their MATHds is $89 \%$, thus suggesting a strong evolutionary pressure to maintain the MATHd of SPOP and relatives virtually unchanged from worms to humans.

It is worth mentioning that rice (Oryza sativa) contains the larger number of MATHd/BTB proteins (about 70) of all the species studied so far, including other monocotyledons (liliopsidae) such as wheat (Triticum monococcum) and sorghum (Sorghum bicolor). The vast majority of these rice's MATHd/BTB proteins have the MATHd at the N-terminus and the BTB/POZ domain at the C-terminus.

In summary, proteins combining the MATH domain with the BTB domain are found very early in the evolution of eukaryotes. The available evidence suggests that they might link specific protein substrates to ubiquitin ligase complexes. Additional research will be required to identify these putative substrates and to determine whether all the MATHd/BTB proteins found in diverse organisms have this function, particularly in rice and C.elegans that contain the larger number of MATHd/BTB genes identified so far. These studies will also help to elucidate whether each of these proteins is specific for a particular substrate or whether a functional redundancy exists, with different MATHd/BTB proteins targeting the same substrates. 


\section{MATH domain-only proteins.}

There is a large number of hypothetical proteins containing one or multiple MATH-domains in tandem and lacking of any other distinguishable associated protein domain (Fig. 3). These proteins are found in plants (Arabidopsis, Medicago, Oryza, and Sorghum), lower eukaryota (Trypanosoma, Dyctiostelium, Theileria and Plasmodium), and in lower metazoa such as nematodes (Caenorhabditis sp) (Fig. 4). Many of these proteins are identified by conceptual translation of the genome and therefore some of them could be part of larger genes that might encompass other protein domains. However, it is noteworthy that these MATHd-only sequences represent the majority of the MATHd-encompassing proteins identified in Arabidopsis thaliana and Caenorhabditis sp, but are not very common in other species, including some whose genome have been fully sequenced. The MATHd of these MATHd-only proteins is in general more similar to that of MATHd/BTB proteins (Fig 7), but some of them have more similarity to the MATHd of UBP proteins (see above and Fig 6). The function of these MATHd-encompassing proteins as well as the significance of their elevated number in Arabidopsis and Caenorhabditis are not yet known.

It is noteworthy that TRAF1 could be considered as a MATH-domain only protein. However, TRAF1 is readily identified as a member of the TRAF family by the high homology of its MATH domain to those of other members of the TRAF family.

\section{TRIM37}

A group of MATHd encompassing proteins appears associated to a combination of protein domains known as the tripartite motif (TRIM). The tripartite motif is composed by a RING finger domain, followed by a special type of zinc finger domain coined the ZF-B box and a coiled coil (Fig 2). In humans, there are 37 genes encoding proteins encompassing a tripartite domain ${ }^{39}$ of which only one (trim37) contains a MATHd ${ }^{7}$.

Mutations in the Trim37 gene in humans are causative of Mulibrey Nanism, an autosomal recessive growth disorder that affects several tissues of mesodermal origin ${ }^{40}$. Mulibrey Nanism is characterized by severe growth failure of prenatal onset, constrictive pericardium with consequent hepatomegaly, hypoplasia of several endocrine glands, fibrodysplasia of bones and muscle and

sterility ${ }^{41-43}$. Similar to other members of the MATHd and TRIM ${ }^{44}$ families, TRIM37 seems to function as a E3 ubiquitin ligase, although its physiological substrate(s) is still unknown ${ }^{45}$. 
TRIM/MATHd proteins form a distinctive cluster in the tree (Fig. 5) and have a high degree of conservation (Fig.7). Overall, the TRIM's MATHd is more similar to those of BTB/MATHd proteins than to any other MATHd-encompassing protein subclass. Orthologs of TRIM37 are only found in Coelomata (Metazoa) (Fig 4). Indeed, TRIM37 is found in some insects such as bees (Apis melifera, hymenoptera) but not in others such as Drosophila or Anopheles (both Diptera). However, there are two genes encoding a MATHd-only protein in Anopheles gambiae that have high similarities to the MATHds of the TRIM37 orthologs. TRIM37 seems to be very well conserved in deuterostomia, including the echinoderm Strongylocentrotus purpuratus (sea urchin) (XP791708; not shown) and vertebrata, including mammals, birds and fishes. Interestingly, although TRIM37 is found in zebra fish (Danio rerio) and spotted green pufferfish (Tetraodon nigroviridis), the latter seems to contain a trim37 gene with a truncated MATHd. It is interesting to mention the high level of conservation between different TRIM37 orthologs. For instance, the MATHd of Apis melifera TRIM37 is $69 \%$ identical to rodent's TRIM $37,74 \%$ to chicken's, $71 \%$ to zebra fish's and $74 \%$ to human's. Future research will determine the function of TRIM37 in insects and non-mammalian vertebrates and whether it also has a role in development, as it does in humans.

\section{Meprins}

Meprins are a family of extracellular metalloproteases, which are anchored to the plasmatic membrane and are involved in cleaving growth factors, extracellular matrix proteins, and biologically active peptides ${ }^{46,47}$. Meprins have two subunits, $\alpha$ and $\beta$, that form hetero- and homodimers covalently linked by disulfide bridges. Two of these dimers associate as a tetramer forming the functional meprin complex ${ }^{46}$. The MATHd of meprins is located at the C-terminus and the catalytic astacin-like protease domain at the N-terminus (Fig.2). This MATHd seems to be involved in the oligomeric association of meprin subunits, similar to other MATHds ${ }^{6}$, but it might be also implicated in the recognition, folding and activation of zymogens. The MATHd of meprins form a distinctive cluster in the phylogenetic tree (Fig. 5), and seems to be closely related to the MATHd of TRAFs.

MATHd encompassing meprins appeared late in evolution, as they are only found in vertebrates, including fishes, amphibia, birds and mammals. 


\section{TRAFs}

TNF-Receptors associated Factors (TRAFs) constitute a family of adapter proteins that were initially identified in humans and rodents by their association with different members of the TNFReceptor (TNFR) family. Humans and other mammals contain seven TRAFs (TRAF1 to 7). The TRAF domain (TD) of TRAFs is always located at the C-terminus (Fig. 2). The crystal structures of the TD of human TRAF2 and TRAF3 showed that it is composed by the 7-8 anti-parallel $\beta$-sheet fold (the MATHd, also known as TRAF-C domain) (Fig. 1), followed by a coiled coil (TRAF-N domain). These crystal structures also showed that mammalian TRAFs associate in trimers, with the intertwining coiled coils helping to stabilize the complex ${ }^{1}$. TRAF family-members, with the sole exception of TRAF1, also have a distinctive N-terminal RING finger domain followed by a variable number of zinc finger domains (Fig. 2) ${ }^{1-4,48}$. Although TRAF7 does not contain a TRAF domain, it was arguably included in the TRAF family because it contains a RING finger domain and zinc finger domains that are similar to those found in other TRAF family members and because it seems to participate in the control of TNF-family signaling as do other members of the TRAF family ${ }^{49}$.

Similarly to the other members of the MATHd superfamily, TRAFs have been implicated in the control of proteolysis. Indeed, TRAF2 seems to function as a E3 ubiquitin ligase that regulates TRAF2 and TRAF3 ubiquitination and proteolysis ${ }^{50,51}$. TRAF3 has been shown to regulate NIK proteolysis ${ }^{52}$. However, TRAFs (in particular TRAF2 and TRAF6), working in conjunction with the E2 ligase complex Ubc13/Uev1A, have the ability to self-ubiquitinate or ubiquitinate other proteins with K63-linked poly-ubiquitin chains (Fig. 3). Contrary to K48 ubiquitination, K63 ubiquitination does not target TRAFs or other proteins for degradation, but instead confers TRAF2 and TRAF6 the ability to activate other components of the pathway ${ }^{53}$.

TRAFs are key components of the Toll Receptor (TLR) family and Tumor Necrosis Receptor (TNFR) family signal transduction. TRAFs regulate the recruitment of kinases and other effector proteins to the activated receptor and other signaling complexes. TRAFs also mediate the activation of downstream components of these pathways, control the subcellular relocalization of the receptorligand complexes, and modulate the extent of the response by controlling the degradation of key proteins in the pathway.

\section{Distribution of TRAFs}


TRAFs are broadly represented in metazoans (Fig. 4). The older members of the family seem to be TRAF4 and TRAF6. Indeed, in a theoretical phylogenetic tree based on MATHd similarities (Fig. 5), all TRAF6 and TRAF4 orthologs form two distinctive clusters. Interestingly, a putative TRAF4 ortholog is already found in Hydractinia echinata (snail fur), a member of the phylum cnidaria that includes corals and jellyfishes. Other TRAF4 orthologs are found in nematoda (C. elegans), insects, such as the fruit fly Drosophila (where is known as DTRAF1 ${ }^{54,55}$ ), mosquito (Anopheles gambiae) and bee (Apis melifera), as well as in sea urchin (Strongylocentrotus purpuratus), early chordates, such as Ciona intestinalis (BAE93281, not shown in Fig. 4) and vertebrates.

TRAF6 orthologs have been found so far in insects, such as Drosophila (where is known as DTRAF2) ${ }^{56}$, mosquitoes and bees, as well as in vertebrates.

As suggested by the analyses shown in Fig. 5, TRAF1, TRAF2, TRAF3 and TRAF5 seem to be the members of the TRAF family that appeared later in evolution. These analyses also suggest that these TRAF family members might have originally diversified from a common TRAF4 ancestor. However, there is a TRAF family member (CAH04636) in the sponge Suberites domuncula, a member of the older metazoan taxon still extant ${ }^{57}$. Interestingly, this sponge TRAF shows closer similarities to TRAF3 than to any other TRAF family member when the sequence comparison is performed with the complete protein sequence. Indeed, this TRAF contains a RING and zinc finger domains in its N-terminus and the MATHd at the C-terminus. When only the MATHd is compared, this TRAF still shows higher similarities (about 30\% identities) to both TRAF2 and TRAF3 than to any other member of the TRAF family (Fig. 8). Although it is unclear whether this Suberites domuncula TRAF is a bona fide TRAF3 ortholog, this evidence suggests that TRAF3 might have arisen very early in the evolution of metazoans. TRAF3 is also found in Drosophila ${ }^{58}$, where it is known as DTRAF3 ${ }^{58}$, and in vertebrates.

In contrast, TRAF1, TRAF2 and TRAF5 have been so far only found in vertebrates. Furthermore, TRAF1 and TRAF2's MATHds share a high percentage of homology, suggesting that they arose not long ago from a common ancestor, probably by gene duplication. A similar scenario might have taken place between TRAF3 and TRAF5, which are closely related to each other. Considering also that TRAF1, TRAF2 and TRAF5 are functionally closer to TRAF3 (see below), it seems likely that these TRAFs diversified from a common TRAF3 ancestor early in vertebrate 
evolution. In contrast TRAF3 might have split from TRAF4 much earlier in metazoan evolution. However, a much larger representation of TRAF sequences from early metazoans would be necessary to obtain a clearer picture of the phylogeny of TRAFs in this phylum.

Interestingly, several MATHd encompassing genes are encoded by the genome of the slime mold Dictyostelium discoideum (Mycetozoa) and among those, some of these proteins have striking similarities to TRAFs (see below). Dictyostelium is an unicellular amoebae that grows as independent, separate cells that aggregate under adverse conditions, forming colonies of up to 100,000 cells. These colonies are a true multicellular organism, organizing different tissues composed by differentiated cell types and having the ability of regulating its proportions and morphogenesis ${ }^{59}$. Although the mechanism of formation of the multicellular organism is radically different to that of metazoans, many of the underlying molecular and cellular processes, such as differential cell sorting, pattern formation, stimulus-dependent gene expression, and cell-type regulation seem to be common to Dictyostelium and metazoans, thus suggesting that they have arisen from common primitive precursor cells ${ }^{60}$. Genome and proteome based phylogeny analysis supported that mycetozoa are a true sister group of the fugi/metazoa phyla ${ }^{59}$.

Remarkably, a subset of Dictyostelium's MATHd encompassing proteins contains a Nterminal RING and zinc finger domains similar to those found in TRAFs. Furthermore, the number of aminoacids encoded by these TRAF-like genes is also strikingly similar to that of TRAFs. However, based on the homology of their MATHd, Dictyostelium TRAF-like genes are more similar to MATHd/BTB (the case, for instance of DG17, EA61916, EAL61981) and MATHd/TRIM (EAS66947) proteins (Fig. 7). Although still merely speculative, these results suggest that the association of MATHd from BTB proteins to TRAF-like RING (and zinc finger) domains might have been the starting point in TRAFs evolution, an event that might have happened after the branch leading to plants separated from the branch leading to mycetozoa and metazoa ${ }^{59}$.

\section{Evolutionary aspects of TRAFs function}

The analyses on the function of TRAF family members also has provided valuable insights into the evolutionary pathways followed by this protein family.

The older member of the TRAF family for which we have functional information is the cnidarian Hydractinia echinata HyTRAF $1^{61}$. HyTRAF1 has a N-terminal RING finger and 5 zinc finger domains and its TD is more similar to TRAF4 than to any other TRAF. One isoform of this 
TRAF family member lacking the RING and one of the zinc finger domains is exclusively found at the larval and early metamorphic stages, and seems to regulate apoptosis mediated by c-jun $\mathrm{N}$ terminal kinase (JNK) signaling. Additional functional information is provided by Drosophila's DTRAF1 (TRAF4 ortholog), which has 7 zinc finger domains but no RING finger domain ${ }^{54,55}$. DTRAF1 seems to control apoptosis and imaginal discs and photosensory neurons development by regulating the activation of JNK and its upstream kinases Hep and DTAK $1{ }^{62}$. The role of TRAF4 in development is also supported by studies in zebra fish (Danio rerio) ${ }^{63}$ and mouse ${ }^{64}$, where it has been shown to participate in neurulation in vivo. TRAF4 involvement in JNK activation has been also demonstrated in mammals ${ }^{65,66}$. Indeed, TRAF4 seems to regulate JNK activation by binding to MEKK4 and promoting MEKK4 oligomerization ${ }^{66}$. Most interestingly, mice deficient in MEKK4 develop strikingly similar neurulation and skeletal patterning defects to those observed in TRAF4 deficient mice ${ }^{67,68}$.

TRAF6 is also considered one of the older members of the TRAF family. Drosophila's, TRAF6 ortholog, DTRAF2 participates in the control of gene expression by regulating the activation of the NFkB pathways ${ }^{56,62,69}$. Indeed, DTRAF2 is necessary for the expression of the anti-microbial peptides diptericin, diptericin-like protein and drosomycin in response to fungal and gram-positive bacteria infection, thus supporting a role for DTRAF2 (TRAF6) in innate immunity ${ }^{62}$.

The involvement of TRAF6 in the control of innate immune responses has been also demonstrated in mammalians. TRAF6 is a common mediator of the Toll-like Receptors (TLR)/ Interleukin-1 Receptor (IL1R) superfamily. Eleven TLR family members have been identified in mice and ten in humans, which function as receptors for pathogen-associated molecular patterns (PAMPs) controlling host defense responses as part of innate immunity ${ }^{70-73}$. Nine members of this family are already present in Drosophila melanogaster ${ }^{74}$ and 11 in Anopheles gambiae (mosquito) 75 . However, only 4 Drosophila Toll family members have unambiguous orthologs in Anopheles, thus reflecting a very dynamic evolution of this family. The majority of the Toll family members in Drosophila are involved in the control of developmental patterning, and only two of them are also involved in the control of innate immune responses to fungal and gram-positive bacteria infections. However, these Drosophila Toll Receptors do not recognize PAMPs, as do their mammalian counterparts ${ }^{76,77}$, thus strongly suggesting that the Toll-Receptor family evolved to recognize specific types of PAMPs after the diversification of protostomia and deutorostomia. 
TRAF6 does not directly interact with the members of the TLR/IL1R family. Instead, receptor activation recruits different adaptors, such as the myeloid differentiation factor 88 (MyD88), TIRAP, and TRAM. Receptor activated MyD88 will induce the formation of complexes containing TRAF6, IRAK family proteins, and IRF-5. In contrast, receptor activated TRAM will induce the formation of complexes containing TRIF, TRAF6 and RIP-1. In both types of complexes, TRAF6 will then associate with the ubiquitin conjugating enzymes Ubc13 and Uev1A. TRAF6 functions as a ubiquitin ligase (E3) that catalyzes the assembly of K63-linked polyubiquitin chains on itself and on IKK $\gamma / \mathrm{NF} \kappa \mathrm{B}$ essential modulator (NEMO) ${ }^{78}$ (Fig. 3). K63-ubiquitinated-TRAF6 is required for the activation of the MAP3K transforming growth factor $\beta$ activated kinase-1 (TAK-1), and TAK-1 binding proteins (TAB)-1 and $2^{79,80}$. Activated TAK1 will phosphorylate IKK and MKK6, leading to the activation of NFKB, JNK, p38 and ERK (reviewed in ${ }^{73}$ ).

As indicated above, Drosophila's response to fungal and gram-positive bacteria infections is mediated by Toll Receptors that recruit MyD88 upon activation. Similar to what observed with their mammalian counterparts, MyD88 recruitment of DTRAF2 (TRAF6) to the complex is essential for the response ${ }^{77}$. However, Drosophila's response to gram-negative bacteria infection involves the protein IMD, the Drosophila RIP-1 ortholog, and requires the Drosophila E2 ubiquitin ligase Bendless (Uev1A) that catalizes K63-ubiquitination ( ${ }^{81}$ and references therein).

Interestingly, RIP-1 is required for TRIF-mediated NFאB induction in response to TLR-3 and -4 activation in mammalian cells ${ }^{82}$. In this regard, two recent reports have shown that TRIF utilizes TRAF3 for signaling ${ }^{83,84}$. Indeed, similar to TRAF6, TLRs also recruit TRAF3 through MyD88 and IRAK1 and 4, but rather than activating MAP3K and IKK, which induce proinflammatory cytokines, TRAF3 engages TRIF-dependent signaling pathways leading to activation of TBK-1 and IKK- $\varepsilon$, inducing the expression of type I interferons and the anti-inflammatory IL-10 83, 84 . Thus, TRAF3 may play important roles in interferon-dependent responses to viral pathogens, as well as in down-regulating innate immune responses via its effects on IL-10 production. The function of DTRAF3, the Drosophila TRAF3 ortholog ${ }^{58}$ is still unknown. It will be specially interesting to determine whether Drosophila TRAF3 plays also a role in pathogen protection.

As mentioned above, TRAFs were initially identified by their ability to interact with and regulate TNFRs. There are two subclasses of TNFRs. The first subclass contains a cytosolic death domain (DD) and does not normally engage TRAFs for signaling, with the exception of TNFR1, that 
recruits TRAF1 and TRAF2 through their interaction with TRADD. These DD-encompassing TNFRs seem to be the older members of the family. Indeed, the older bona fide TNFR currently on record is Eiger, a Drosophila TNFR family member which encompasses a death domain (DD). Eiger regulates apoptosis by engaging similar signal transduction pathways than those used by other mammalian DD-encompassing TNFRs ${ }^{85}$. The second subclass of TNFRs does not encompass any recognizable protein domain in the cytosolic tail, but its members contain peptide sequences that support the specific interaction of TRAFs. All available information suggests that this TNFR subclass has appeared during vertebrate evolution.

A total of 20 mammalian TNFR family members that utilize TRAFs for signaling have been described so far ${ }^{2}$. TRAF6 regulates some of these TNFRs by specifically interacting with the hexapeptide motif $\operatorname{PxExx}(\mathrm{Ar} / \mathrm{Ac})$, where the last amino-acid residue is either aromatic or acidic, in the cytosolic tail of TNFRs ${ }^{86}$. In contrast, TRAF1, TRAF2, TRAF3 and TRAF5 recognize the tetrapeptide sequence $(\mathrm{P} / \mathrm{S} / \mathrm{A} / \mathrm{T}) \mathrm{x}(\mathrm{Q} / \mathrm{E}) \mathrm{E}$. TRAF4 has been proposed to interact with and regulate the Nerve Growth Factor Receptor (NGFR) ${ }^{87,88}$, which seems to be one of the older members of the TNFR family, and the glucocorticoid-induced TNFR (GITR) ${ }^{89}$, but its role as a TNFR regulator remains controversial.

The fact that TRAF1, TRAF2, TRAF3 and TRAF5 recognize the same peptide motif in the cytosolic tail of various TNFR family members further support the idea that these TRAFs have diverged recently, most likely from a common TRAF3 ancestor (see above). Interestingly, TRAF1 and TRAF2 are closer to each other than to any other TRAF family member, and functional evidence suggests that TRAF1 regulates TRAF2 activities ${ }^{90-92}$. Similarly, TRAF3 and TRAF5 are more similar to each other than to any other TRAF. However, TRAF5 is able to activate NFkB, whereas TRAF3 has an inhibitory role on the activation of NFKB mediated by TRAF2 and TRAF5 ${ }^{93}$. Altogether, these results suggest that TRAF2 might have split from TRAF3 first, and later TRAF1 and TRAF5 diverged from TRAF2 and TRAF3, respectively. Interestingly, TRAF1, TRAF2 and TRAF5 are only found in vertebrates. Given the fast diversification of the TNFR family during vertebrate evolution, these members of the TRAF family might have emerged to increase the functional versatility of the members of the TNFR family.

The role of TRAFs in regulating TNFRs function has been more studied in the immune system, where they regulate differentiation, proliferation, and apoptosis, and are essential for 
adaptive immune responses. However, there are also some developmental functions associated to TRAFs that seem to be also related to their role in the regulation of TNFR activities. TRAF6 has been shown to be involved in the control of bone formation and hair follicular development through its role in regulating RANK and XEDAR ${ }^{94-98}$. TRAF4 is also involved in development by controlling neurulation ${ }^{64}$, although whether it is through the regulation of a TNFR family member is not know.

In summary, the available evidence suggests that TRAF4 and TRAF6 are the older members of the TRAF family, with TRAF3 probably diversifying from TRAF4 early in metazoan evolution. TRAF2, TRAF1 and TRAF5 appeared later during vertebrate evolution, most likely splitting from a TRAF3 ancestor. However, as new information on new genomes is gathered, the phylogenetic relations between the different TRAF family members should became more evident.

\section{Viral immune evasion strategies interfering with MATH-dependent pathways}

Protein sequence comparison analyses also identified the existence of 3 TRAF proteins in fish infecting iridoviruses. These viral TRAFs form a distinctive cluster in the tree shown in Fig. 5. These viral TRAFs seem to be more related to TRAF2, sharing a 56\% homology with zebra fish TRAF2 and 43\% homology with human TRAF2. Two of these genes also encode a zinc finger domain at the N-terminus of the molecule (AAL98835 and BAD98248), while the other one (YP249563) is a MATHd-only protein. The function of these iridovirus TRAFs is yet not known, but they are likely to interfere with the signaling of the host TRAF family proteins.

Other viral proteins have been described to interfere with the function of various MATHd proteins of the host, although they are not MATHd proteins themselves. Two of these proteins (LMP-1 and EBNA-1) are encoded by the genome of Epstein-Barr virus (EBV), a member of the herpes virus family that infects over $90 \%$ of the world adult population and can cause several immunological disorders and cancer in immunosuppressed individuals ${ }^{99}$. The latent membrane protein (LMP)-1 mimics an activated CD40 and recruits various members of the TRAF family for signaling, but in a seemingly deregulated manner, leading to amplified and sustained B cell

activation ${ }^{100-104}$. The Epstein-Barr nuclear antigen 1 (EBNA1) protein interacts with USP7 and contributes to the survival of the virus-infected cells by out-competing p53 from binding to USP7 and enforcing p53 degradation ${ }^{11}$. 
Herpes simplex virus type 1 immediate-early regulatory protein ICP0 also interfere with USP7 function. ICP0 stimulates lytic infection and reactivation from latency. ICP0 functions as a ubiquitin E3 ligase that ubiquitinate itself and is subsequently degraded by the proteasome. USP7 removes the ubiquitin chains from ICP0, thus preventing its degradation and preserving its function. 12,105

Kaposi's sarcoma herpesvirus ${ }^{106}$ and human molluscipox virus ${ }^{107}$ encode homologs of the Flice/caspase 8 inhibitory protein (v-Flip) that interact with TRAFs to interfere with the proapoptotic pathways of the host cell.

\section{SIAH}

Drosophila seven in absentia (sina) protein and several orthologous genes in other species deserve special mention. Sina proteins are found already in plants and have remain very well conserved in evolution. Humans have two members of this family known as seven in absentia homologous (SIAH)-1 and 2. SIAHs are E3 ubiquitin ligases, acting either as single proteins or as part of a multiprotein complex that is analogous to the Skp1-cullin-1-F-box (SCF) complex ${ }^{108}$. SIAH and TRAFs have only $10 \%$ sequence homology in their C-terminal domains based on a threedimensional structure-based sequence alignment. However, the crystal structure of SIAH1a shows that its C-terminal domain forms an eight-stranded antiparallel $\beta$-sandwich, a fold that is virtually identical to a MATH domain (Fig. 1) ${ }^{109}$. SIAH also have a N-terminal RING finger domains followed by 2 Zinc finger domains, besides the C-terminal TD-like domain ${ }^{109}$, which further extents the similarities between SIAHs and TRAFs. However, the RING and zinc finger domains found in SIAH and in TRAFs are of different subtypes, further suggesting that these two protein families are not related

Similar to TRAFs and other MATHd encompassing proteins, SIAHs are E3 ubiquitin ligases that regulate ubiquitination and degradation of proteins implicated in a variety of physiological processes, including cell growth, differentiation, angiogenesis, oncogenesis, inflammation and stress ( ${ }^{110}$ and references therein). Interestingly, one of these proteins targeted by SIAH is TRAF2. Indeed, SIAH interacts with TRAF2 through its TD and catalyzes its ubiquitination and degradation under stress conditions ${ }^{111}$. 
There are two possibilities to explain the similarities between sina C-terminus fold and the MATHd. First, it would be possible that Sina and MATHd genes were originally related, sharing a common ancestor very early in eukaryotes evolution, but have since then diversified at sequence level beyond recognition while preserving the 8 anti-parallel $\beta$-sheet fold characteristic of the MATHd. A second possibility would be that these genes are an unparallel example of convergent evolution, having evolved to develop similar protein structure and function. The answer to this question awaits further research.

\section{Concluding remarks}

In this chapter we have overviewed different aspects of the evolution of the MATHd. This fold appeared early in the evolution of eukaryotes and has remained very well preserved. Indeed, MATHd encompassing proteins from distant species can still associate both physically and functionally ${ }^{55}$. Furthermore, MATHd encompassing proteins from different families can also interact with each other in vitro ${ }^{7}$. Functional diversification has been achieved by association of the MATHd with other protein domains. However, the overall function of the vast majority of MATHd encompassing protein families involves protein processing by participating in different aspects of protein ubiquitination and protein degradation.

Current efforts on the sequencing of genomes from different organisms, including low eukaryotes with biomedical relevance, will provide new information on the origins of the MATHd. Furthermore, in addition to the large pool of functional data already available on TRAFs, recent reports have provided the first insights into the function of other MATHd encompassing protein families, such as UBPs (USP7) and MATHd/BTB (SPOP, MEL26) proteins. These studies illustrate the seminal roles of MATHd proteins in different aspects of physiology and predict new exciting discoveries to come.

\section{Acknowledgements:}

We are thankful to NIH for providing public access to excellent and comprehensive databases. We are indebted to the Ministerio de Educación y Ciencia (BES2005-8383), Programa Ramón y Cajal, SAF2004-7675 and NIH grants DK67515, HD044803 and AI070859. We are grateful to Drs. Alexey Eroshkin and Yoshinobu Igarashi for helping with data analysis. 


\section{Figure Legends}

Figure 1. Models of the MATHd of human TRAF2 (1CZY), USP7 (2FOP) and SIAH (1K2F) were modeled using protein explorer. The MATHd of DTRAF-1, TRIM37, SPOP, Meprin and examples of Dictyostelium, Arabidopsis and C.elegans MATHds were constructed by threading on the structure of the MATHd of TRAF2 ${ }^{16,17}$, using FFAS and MODELER ${ }^{112,113}$.

Figure 2. Proteins encompassing MATH domains and their association with other protein domains were identified using the Conserved Domain Search service (CD-Search) ${ }^{114}$, the Conserved Domain Database for protein classification (CDD) ${ }^{115}$ and the Conserved Domain Architecture Retrieval Tool $(C D A R T){ }^{116}$, three NCBI web-based tools for detection of structural and functional domains in protein sequences. A. MATHd encompassing ubiquitin proteases (USP7 family), B. MATHd/Rlu proteins. C. MATHd-only proteins. D. MATHd encompassing broad-complex, tramtrack and bric a brac (BTB) domain protein family. E. MATHd/filament protein. F. TRAF family. G. TRIM37 family. H. Meprin family.

MATH: meprin and TRAF homologous domain (cd00121); UBP: ubiquitin protease domain(peptidase C19C, cd02659); RING: Really Interesting New Gene finger domain (cd00162); Rlu; pseudo-uridine synthase Rlu (cd02869); POZ/BTB Pox virus and Zinc finger/broad-complex, tramtrack and bric a brac domain (smart00225); Filament: intermediate filament protein domain (pfam00038); ZF: TRAF-type zinc finger domain (pfam02176); CC: coiled coil, TRAF-N domain; ZF-Box: B box zinc finger (pfam00643); BBC: B-box C-terminal domain, coiled coil (smart00502); Astacin: astacin (peptidase family M12A) domain (pfam01400); MAM: Meprin and mu domain (smart00137) ; EGF: epidermal growth factor-like domain (smart00181).

Figure 3. MATHd proteins regulate protein processing. The selective degradation of many proteins in eukaryotic cells is carried out by the ubiquitin system ${ }^{117}$. In this pathway, proteins are targeted for degradation by covalent ligation at lysine (K)48 to ubiquitin, one of the most phylogenetically well-conserved proteins in eukaryota ${ }^{118}$. Ubiquitin-mediated protein degradation by the proteasome is key for the control of numerous biological processes, including the control of cell-cycle, transcriptional regulation, and signal transduction, to mention just a few (reviewed in ${ }^{117}$ ). A different type of ubiquitination (K63) does not result in degradation of the targeted proteins, but instead is necessary for the activation of and signaling from these proteins ${ }^{53}$. UBP (USP) can counteract the effect of E3 ligases by removing ubiquitin chains from proteins. Meprins are a family 
of extracellular metalloproteases that are involved in cleaving growth factors, extracellular matrix proteins, and biologically active peptides ${ }^{46,47}$.

Figure 4. Phylogenetic tree of MATHd in living organisms and viruses. The nomenclature and phylogenetic relations of the NCBI Taxonomy browser (http://www.ncbi.nlm.nih.gov/entrez/query.fcgi?db=Taxonomy) were followed. Only those branches with species containing MATHd encompassing gene(s) are represented. The letters refer to the different subclasses of MATHd encompassing protein families described in Figure 2.

Figure 5. Rooted tree representing the theoretical phylogenetic relations of MATHd encompassing proteins. Sequence similarities are determined using MUSCLE 119, 120, and a BLOSUM62 matrix that is based on the likelihood method estimating the occurrence of each possible pairwise substitution ${ }^{121}$. Species listed (by alphabetical order): A.f. Aspergillus fumigatus; A.g. Anopheles gambiae; A.m. Apis melifera; A.t. Arabidopsis thaliana; C.a. Candida albicans; C.b. Caenorhabditis brigsae; C.e. Caenorhabditis elegans; C.f. Canis familiaris; C.g. Candida glabrata; C.h. Cryptosporidium hominis; C.n. Cryptococcus neoformans; C.p. Cryptosporidium parvum; D.d. Dictyostelium discoideum; D.m. Drosophila melanogaster; D.r. Danio rerio; G.g. Gallus gallus; G.z. Gibberella zeae; H.e. Hydractinia echinata; H.s. Homo sapiens; K.l. Kluyveromyces lactis; L.m. Leishmania major; M.g. Magnaporthe grisea; M.m. Mus musculus; N.c. Neurospora crassa; O.m. Oncorhynchus mykiss; O.s. Oryza sativa; P.b. Plasmodium berghei; P.f. Plasmodium falciparum; R.n. Rattus norvegicus; S.b. Sorghum bicolor; S.c. Saccharomyces cerevisiae; S.d. Suberites domuncula; S.p. Schizosaccharomyces pombe; St.p. Strongylocentrotus purpuratus; T.a. Theileria annulata; T.b. Trypanosoma brucei; T.c. Trypanosoma cruzi; T.m. Triticum monococcum; T.n. Tetraodon nigroviridis; T.p. Theileria parva; U.m. Ustilago maydis; X.1. Xenopus laevis; X.p. Xenopus tropicales; Y.1. Yarrowia lipolytica.

\section{Figure 6 Protein sequence alignment of the MATHd of UBPs.}

Multiple alignment was initially performed using all available MATHd sequences, to obtain the same order shown in the tree shown in Fig. 5. Then, only MATHd containing UBP sequences were selected and realigned. 
Figure 7. Protein sequence alignment of the MATHd of TRIM and BTB proteins. Multiple alignment was initially performed using all available MATHd sequences, to obtain the same order shown in the tree shown in Fig. 5. Then, MATHd sequences of members of the TRIM, BTB/POZ and MATHd only families were selected and realigned.

Figure 8. Protein sequence alignment of the MATHd of TRAFs and Meprins. Multiple alignment was initially performed using all available MATHd sequences, to obtain the same order shown in the tree shown in Fig. 5. Then, only MATHd sequences of TRAFs and Meprins were selected and realigned..

\section{Bibliography}

1. Chung JY, Park YC, Ye H, Wu H. All TRAFs are not created equal: common and distinct molecular mechanisms of TRAF-mediated signal transduction. J Cell Sci. 2002;115:679-688.

2. Zapata JM. TNF-receptor-associated factors as targets for drug development. Expert Opin. Ther.Targets. 2003;7(3):411-425.

3. Bradley JR, Pober JS. Tumor necrosis factor receptor-associated factors (TRAFs). Oncogene. 2001;20:6482-6491.

4. Bishop GA. The multifaceted roles of TRAFs in the regulation of B-cell function. Nat Rev Immunol. Oct 2004;4(10):775-786.

5. Uren AG, Vaux DL. TRAF proteins and meprins share a conserved domain. Trends Biochem. Sci. 1996;21(7):244-245.

6. Sunnerhagen M, Pursglove S, Fladvad M. The new MATH: homology suggests shared binding surfaces in meprin tetramers and TRAF trimers. FEBS Lett. Oct 23 2002;530(1-3):1-3.

7. Zapata JM, Pawlowski K, Haas E, Ware CF, Godzik A, Reed JC. A diverse family of proteins containing Tumor Necrosis Factor Receptor-associated Factor domains. J Biol Chem. 2001;276:24242-24252.

8. Amerik AY, Hochstrasser M. Mechanism and function of deubiquitinating enzymes. Biochim Biophys Acta. Nov 29 2004;1695(1-3):189-207.

9. Nijman SM, Luna-Vargas MP, Velds A, et al. A genomic and functional inventory of deubiquitinating enzymes. Cell. Dec 2 2005;123(5):773-786.

10. Semple CA. The comparative proteomics of ubiquitination in mouse. Genome Res. Jun 2003;13(6B):1389-1394.

11. Saridakis V, Sheng Y, Sarkari F, et al. Structure of the p53 binding domain of HAUSP/USP7 bound to Epstein-Barr nuclear antigen 1 implications for EBVmediated immortalization. Mol Cell. Apr 1 2005;18(1):25-36. 
12. Everett R, Meredith M, Orr A, Cross A, Kathoria M, Parkinson J. A novel ubiquitin-specific protease is dynamically associated with the PML nuclear domain and binds to a herpesvirus regulatory protein. EMBO J. 1997;16:566-577.

13. Sheng Y, Saridakis V, Sarkari F, et al. Molecular recognition of p53 and MDM2 by USP7/HAUSP. Nat Struct Mol Biol. Feb 122006.

14. Ye H, Park Y, Kreishman M, Kieff E, Wu H. The structural basis for the recognition of diverse receptor sequences by TRAF2. Mol Cell. 1999;4:321-330.

15. Ni C-Z, Welsh K, Leo E, et al. Molecular basis for CD40 signaling mediated by Traf3. Proc Natl Acad Sci USA. 2000;97:10395-10399.

16. McWhirter S, Pullen S, Holton J, Crute J, Kehry M, Alber T. Cristalographic analyses of CD40 recognition and signaling by human TRAF2. Proc Natl Acad Sci USA. 1999;96:8408-8413.

17. Park Y, Burkitt V, Villa A, Tong L, Wu H. Structural basis for self-association and receptor recognition of human TRAF2. Nature. 1999;398:533-538.

18. $\mathrm{Hu} \mathrm{M}, \mathrm{Gu} \mathrm{L}, \mathrm{Li}$ M, Jeffrey PD, Gu W, Shi Y. Structural Basis of Competitive Recognition of $\mathrm{p} 53$ and MDM2 by HAUSP/USP7: Implications for the Regulation of the p53-MDM2 Pathway. PLoS Biol. Feb 2006;4(2):e27.

19. Li M, Brooks CL, Wu-Baer F, Chen D, Baer R, Gu W. Mono- versus polyubiquitination: differential control of p53 fate by Mdm2. Science. Dec 12 2003;302(5652):1972-1975.

20. Cummins JM, Rago C, Kohli M, Kinzler KW, Lengauer C, Vogelstein B. Tumour suppression: disruption of HAUSP gene stabilizes p53. Nature. Apr 1 2004;428(6982): 1 p following 486.

21. Li M, Brooks CL, Kon N, Gu W. A dynamic role of HAUSP in the p53-Mdm2 pathway. Mol Cell. Mar 26 2004;13(6):879-886.

22. Li M, Chen D, Shiloh A, et al. Deubiquitination of p53 by HAUSP is an important pathway for p53 stabilization. Nature. 2002;416:648-653.

23. Raychaudhuri S, Niu L, Conrad J, Lane BG, Ofengand J. Functional effect of deletion and mutation of the Escherichia coli ribosomal RNA and tRNA pseudouridine synthase RluA. J Biol Chem. Jul 2 1999;274(27):18880-18886.

24. Traub P, Mothes E, Shoeman R, Kuhn S, Scherbarth A. Characterization of the nucleic acid-binding activities of the isolated amino-terminal head domain of the intermediate filament protein vimentin reveals its close relationship to the DNAbinding regions of some prokaryotic single-stranded DNA-binding proteins. $J \mathrm{Mol}$ Biol. Nov 5 1992;228(1):41-57.

25. Bardwell VJ, Treisman R. The POZ domain: a conserved protein-protein interaction motif. Genes Dev. Jul 15 1994;8(14):1664-1677.

26. Stogios PJ, Downs GS, Jauhal JJ, Nandra SK, Prive GG. Sequence and structural analysis of BTB domain proteins. Genome Biol. 2005;6(10):R82.

27. Ahmad KF, Engel CK, Prive GG. Crystal structure of the BTB domain from PLZF. Proc Natl Acad Sci U S A. Oct 13 1998;95(21):12123-12128.

28. van den Heuvel S. Protein degradation: CUL-3 and BTB--partners in proteolysis. Curr Biol. Jan 20 2004;14(2):R59-61.

29. $\mathrm{Xu} \mathrm{L}$, Wei Y, Reboul J, et al. BTB proteins are substrate-specific adaptors in an SCF-like modular ubiquitin ligase containing CUL-3. Nature. Sep 18 2003;425(6955):316-321. 
30. Pintard L, Willis JH, Willems A, et al. The BTB protein MEL-26 is a substratespecific adaptor of the CUL-3 ubiquitin-ligase. Nature. Sep 18 2003;425(6955):311-316.

31. Geyer R, Wee S, Anderson S, Yates J, Wolf DA. BTB/POZ domain proteins are putative substrate adaptors for cullin 3 ubiquitin ligases. Mol Cell. Sep 2003;12(3):783-790.

32. Nagai Y, Kojima T, Muro Y, et al. Identification of a novel nuclear speckle-type protein, spop. FEBS Letters. 1997;418:23-26.

33. Reed JC, Doctor K, Rojas A, et al. Comparative analysis of apoptosis and inflammation genes of mice and humans. Genome Res. Jun 2003;13(6B):13761388.

34. Liu L, Andrews LG, Tollefsbol TO. Loss of the human polycomb group protein BMI1 promotes cancer-specific cell death. Oncogene. Feb 272006.

35. Valk-Lingbeek ME, Bruggeman SW, van Lohuizen M. Stem cells and cancer; the polycomb connection. Cell. Aug 20 2004;118(4):409-418.

36. Park IK, Morrison SJ, Clarke MF. Bmi1, stem cells, and senescence regulation. $J$ Clin Invest. Jan 2004;113(2):175-179.

37. Hernandez-Munoz I, Lund AH, van der Stoop P, et al. Stable X chromosome inactivation involves the PRC1 Polycomb complex and requires histone MACROH2A1 and the CULLIN3/SPOP ubiquitin E3 ligase. Proc Natl Acad Sci U S A. May 24 2005;102(21):7635-7640.

38. Kwon JE, La M, Oh KH, et al. BTB domain-containing speckle-type POZ protein (SPOP) serves as an adaptor of DAXX for ubiquitination by Cul3-based ubiquitin ligase. J Biol Chem. Mar 82006.

39. Reymond A, Meroni G, Fantozzi A, et al. The tripartite motif family identifies cell compartments. Embo J. May 1 2001;20(9):2140-2151.

40. Avela K, Lipsanen-Nyman M, Idanheimo N, et al. Gene encoding a new RINGB-box coiled-coil protein is mutated in mulibrey nanism. Nat Genet. 2000;25:298301.

41. Lapunzina P, Rodriguez JI, de Matteo E, Gracia R, Moreno F. Mulibrey nanism: three additional patients and a review of 39 patients. Am J Med Genet. 1995;55:349-355.

42. Lipsanen-Nyman M, Perheentupa J, Rapola J, Sovijarvi A, Kupari M. Mulibrey heart disease: clinical manifestations, long-term course, and results of pericardiectomy in a series of 49 patients born before 1985. Circulation. Jun 10 2003;107(22):2810-2815.

43. Karlberg S, Tiitinen A, Lipsanen-Nyman M. Failure of sexual maturation in Mulibrey nanism. N Engl J Med. Dec 9 2004;351(24):2559-2560.

44. Meroni G, Diez-Roux G. TRIM/RBCC, a novel class of 'single protein RING finger' E3 ubiquitin ligases. Bioessays. Nov 2005;27(11):1147-1157.

45. Kallijarvi J, Avela K, Lipsanen-Nyman M, Ulmanen I, Lehesjoki AE. The TRIM37 gene encodes a peroxisomal RING-B-box-coiled-coil protein: classification of mulibrey nanism as a new peroxisomal disorder. Am J Hum Genet. 2002;70:1215-1228.

46. Bond JS, Beynon RJ. The astacin family of metalloendopeptidases. Protein Sci. 1995;4:1247-1261. 
47. Villa JP, Bertenshaw GP, Bylander JE, Bond JS. Meprin proteolytic complexes at the cell surface and in extracellular spaces. Biochem Soc Symp. 2003(70):53-63.

48. Laine A, Ronai Z. Ubiquitin chains in the ladder of MAPK signaling. Sci STKE. Apr 26 2005;2005(281):re5.

49. Xu LG, Li LY, Shu HB. TRAF7 potentiates MEKK3-induced AP1 and CHOP activation and induces apoptosis. J Biol Chem. Apr 23 2004;279(17):1727817282.

50. Brown KD, Hostager BS, Bishop GA. Regulation of TRAF2 signaling by selfinduced degradation. J Biol Chem. May 31 2002;277(22):19433-19438.

51. Hostager BS, Haxhinasto SA, Rowland SL, Bishop GA. Tumor necrosis factor receptor-associated factor 2 (TRAF2)-deficient B lymphocytes reveal novel roles for TRAF2 in CD40 signaling. J Biol Chem. Nov 14 2003;278(46):45382-45390.

52. Liao G, Zhang M, Harhaj EW, Sun SC. Regulation of the NF-kappaB-inducing kinase by tumor necrosis factor receptor-associated factor 3-induced degradation. J Biol Chem. Jun 18 2004;279(25):26243-26250.

53. Chen ZJ. Ubiquitin signalling in the NF-kappaB pathway. Nat Cell Biol. Aug 2005;7(8):758-765.

54. Liu H, Su Y-C, Becker E, Treisman J, Skolnik E. A Drosophila TNF-receptorassociated factor (TRAF) binds the Ste20 kinase Misshapen and activates Jun kinase. Curr. Biol. 1999;9:101-104.

55. Zapata JM, Matsuzawa S, Godzik A, Leo E, Wasserman SA, Reed JC. The drosophila TNF-receptor associated factor -1 (DTRAF1) interacts with pelle and regulates NFkB activity. J Biol Chem. 2000;275:12102-12107.

56. Shen B, Liu H, Skolnik EY, Manley JL. Physical and functional interactions between Drosophila TRAF2 and pelle kinase contribute to dorsal activation. Proc Natl Acad Sci USA. 2001;98:8596-8601.

57. Muller WE, Muller IM. Analysis of the sponge [Porifera] gene repertoire: implications for the evolution of the metazoan body plan. Prog Mol Subcell Biol. 2003;37:1-33.

58. Grech A, Quinn R, Srinivasan D, Badoux X, Brink R. Complete structural characterisation of the mammalian and Drosophila TRAF genes: implications for TRAF evolution and the role of RING finger splice variants. Mol Immunol. AugSep 2000;37(12-13):721-734.

59. Eichinger L, Pachebat JA, Glockner G, et al. The genome of the social amoeba Dictyostelium discoideum. Nature. May 5 2005;435(7038):43-57.

60. Kessin RH. Dictyostelium. Vol xiv. Cambridge: Cambridge University Press; 2001.

61. Mali B, Frank U. Hydroid TNF-receptor-associated factor (TRAF) and its splice variant: a role in development. Mol Immunol. Jun 2004;41(4):377-384.

62. Cha GH, Cho KS, Lee JH, et al. Discrete functions of TRAF1 and TRAF2 in Drosophila melanogaster mediated by c-Jun N-terminal kinase and NF-kappaBdependent signaling pathways. Mol Cell Biol. Nov 2003;23(22):7982-7991.

63. Kedinger V, Alpy F, Tomasetto C, Thisse C, Thisse B, Rio MC. Spatial and temporal distribution of the traf4 genes during zebrafish development. Gene Expr Patterns. Apr 2005;5(4):545-552. 
64. Regnier $\mathrm{CH}$, Masson $\mathrm{R}$, Kedinger $\mathrm{V}$, et al. Impaired neural tube closure, axial skeleton malformations, and tracheal ring disruption in TRAF4-deficient mice. Proc Natl Acad Sci U S A. Apr 16 2002;99(8):5585-5590.

65. $\mathrm{Xu} \mathrm{YC}, \mathrm{Wu} \mathrm{RF}, \mathrm{Gu} \mathrm{Y}$, et al. Involvement of TRAF4 in oxidative activation of cJun N-terminal kinase. J Biol Chem. Aug 2 2002;277(31):28051-28057.

66. Abell AN, Johnson GL. MEKK4 is an effector of the embryonic TRAF4 for JNK activation. J Biol Chem. Oct 28 2005;280(43):35793-35796.

67. Chi H, Sarkisian MR, Rakic P, Flavell RA. Loss of mitogen-activated protein kinase kinase kinase 4 (MEKK4) results in enhanced apoptosis and defective neural tube development. Proc Natl Acad Sci U S A. Mar 8 2005;102(10):38463851.

68. Abell AN, Rivera-Perez JA, Cuevas BD, et al. Ablation of MEKK4 kinase activity causes neurulation and skeletal patterning defects in the mouse embryo. Mol Cell Biol. Oct 2005;25(20):8948-8959.

69. Kopp E, Medzhitov R, Carothers J, et al. ECSIT is an evolutionarily conserved intermediate in the Toll/IL-1 signal transduction pathway. Genes Dev. Aug 15 1999;13(16):2059-2071.

70. Janeway CA, Jr., Medzhitov R. Innate immune recognition. Annu Rev Immunol. 2002;20:197-216.

71. Iwasaki A, Medzhitov R. Toll-like receptor control of the adaptive immune responses. Nat Immunol. Oct 2004;5(10):987-995.

72. Kaisho T, Akira S. Pleiotropic function of Toll-like receptors. Microbes Infect. Dec 2004;6(15):1388-1394.

73. Akira S, Uematsu S, Takeuchi O. Pathogen recognition and innate immunity. Cell. Feb 24 2006;124(4):783-801.

74. Royet J, Reichhart JM, Hoffmann JA. Sensing and signaling during infection in Drosophila. Curr Opin Immunol. Feb 2005;17(1):11-17.

75. Christophides GK, Zdobnov E, Barillas-Mury C, et al. Immunity-related genes and gene families in Anopheles gambiae. Science. Oct 4 2002;298(5591):159165.

76. Kimbrell DA, Beutler B. The evolution and genetics of innate immunity. Nature Rev. 2001;2:256-267.

77. Brennan CA, Anderson KV. Drosophila: the genetics of innate immune recognition and response. Annu Rev Immunol. 2004;22:457-483.

78. Deng L, Wang C, Spencer E, et al. Activation of the IkB kinase complex TRAF6 requires a dimeric ubiquitin-conjugating enzyme complex and a unique polyubiquitin chain. Cell. 2000;103:351-361.

79. Jiang Z, Ninomiya-Tsuji J, Qian Y, Matsumoto K, Li X. Interleukin-1 (IL-1) receptor-associated kinase-dependent IL-1-induced signaling complexes phosphorylate TAK1 and TAB2 at the plasma membrane and activate TAK1 in the cytosol. Mol Cell Biol. Oct 2002;22(20):7158-7167.

80. Wang C, Deng L, Hong M, Akkaraju GR, Inoue J-I, Chen ZJ. TAK1 is a ubiquitin-dependent kinase of MKK and IKK. Nature. 2001;412:346-351.

81. Zhou R, Silverman N, Hong M, et al. The role of ubiquitination in Drosophila innate immunity. J Biol Chem. Oct 7 2005;280(40):34048-34055. 
82. Cusson-Hermance N, Khurana S, Lee TH, Fitzgerald KA, Kelliher MA. Rip1 mediates the Trif-dependent toll-like receptor 3- and 4-induced NF-\{kappa $\}$ B activation but does not contribute to interferon regulatory factor 3 activation. $J$ Biol Chem. Nov 4 2005;280(44):36560-36566.

83. Oganesyan G, Saha SK, Guo B, et al. Critical role of TRAF3 in the Toll-like receptor-dependent and -independent antiviral response. Nature. Nov 232005.

84. Hacker H, Redecke V, Blagoev B, et al. Specificity in Toll-like receptor signalling through distinct effector functions of TRAF3 and TRAF6. Nature. Nov 232005.

85. Igaki T, Kanda H, Yamamoto-Goto Y, et al. Eiger, a TNF superfamily ligand that triggers the Drosophila JNK pathway. Embo J. 2002;21:3009-3018.

86. Ye H, Arron JR, Lamothe B, et al. Distinct molecular mechanism for initiating TRAF6 signalling. Nature. 2002;418:443-447.

87. Ye X, Mehlen P, Rabizadeh S, et al. TRAF family proteins interact with the common neurotrophin receptor and modulate apoptosis induction. J Biol Chem. 1999;274:30202-30208.

88. Krajewska M, Krajewski S, Zapata JM, et al. TRAF-4 expression in epithelial progenitor cells. Analysis in normal adult, fetal, and tumor tissues. Amer J Pathol. 1998;152:1549-1561.

89. Esparza EM, Arch RH. TRAF4 functions as an intermediate of GITR-induced NF-kappaB activation. Cell Mol Life Sci. Dec 2004;61(24):3087-3092.

90. Zapata JM, Reed JC. TRAF1: Lord without a RING. Science STKE. 2002; www.stke.org/cgi/content/full/OC sigtrans;2002/133/pe27n.

91. Zapata JM, Krajewska M, Morse HC, 3rd, Choi Y, Reed JC. TNF receptorassociated factor (TRAF) domain and Bcl-2 cooperate to induce small B cell lymphoma/chronic lymphocytic leukemia in transgenic mice. Proc Natl Acad Sci U S A. Nov 23 2004;101(47):16600-16605.

92. Xie P, Hostager BS, Munroe ME, Moore CR, Bishop GA. Cooperation between TNF receptor-associated factors 1 and 2 in CD40 signaling. $J$ Immunol. May 1 2006;176(9):5388-5400.

93. Hauer J, Puschner S, Ramakrishnan P, et al. TNF receptor (TNFR)-associated factor (TRAF) 3 serves as an inhibitor of TRAF2/5-mediated activation of the noncanonical NF-\{kappa\}B pathway by TRAF-binding TNFRs. Proc Natl Acad Sci U S A. Feb 22 2005;102(8):2874-2879.

94. Naito A, Azuma S, Tanaka S, et al. Severe osteopetrosis, defective interleukin-1 signalling and lymph node organogenesis in TRAF6-deficient mice. Genes to Cells. 1999;4:353-362.

95. Lomaga M, Yeh W-C, Sarosi I, et al. TRAF6 deficiency results in osteopetrosis and defective interleukin-1, CD40, and LPS signaling. Genes Dev. 1999;13:10151024.

96. Armstrong AP, Tometsko ME, Glaccum M, Sutherland CL, Cosman D, Dougall WC. A RANK/TRAF6-dependent Signal Transduction Pathway Is Essential for Osteoclast Cytoskeletal Organization and Resorptive Function. J Biol Chem. Nov 15 2002;277(46):44347-44356.

97. Mizukami J, Takaesu G, Akatsuka H, et al. Receptor activator of NF-kappaB ligand (RANKL) activates TAK1 mitogen-activated protein kinase kinase kinase 
through a signaling complex containing RANK, TAB2, and TRAF6. Mol Cell Biol. Feb 2002;22(4):992-1000.

98. Naito A, Yoshida H, Nishioka E, et al. TRAF6-deficient mice display hypohidrotic ectodermal dysplasia. Proc Natl Acad Sci U S A. Jun 25 2002;99(13):8766-8771.

99. Williams H, Crawford DH. Epstein-barr virus: impact of scientific advance on clinical practice. Blood. Oct 182005.

100. Bishop GA, Hostager BS. Signaling by CD40 and its mimics in B cell activation. Immunol Res. 2001;24(2):97-109.

101. Bishop GA, Busch LK. Molecular mechanisms of B-lymphocyte transformation by Epstein-Barr virus. Microbes Infect. Jul 2002;4(8):853-857.

102. Lam N, Sugden B. CD40 and its viral mimic, LMP1: similar means to different ends. Cell Signal. Jan 2003;15(1):9-16.

103. Uchida J, Yasui T, Takaoka-Shichijo Y, et al. Mimicry of CD40 signals by Epstein-Barr virus LMP1 in B lymphocyte responses. Science. 1999;286(5438):300-303.

104. Brown KD, Hostager BS, Bishop GA. Differential signaling and tumor necrosis factor receptor-associated factor (TRAF) degradation mediated by CD40 and the Epstein-Barr virus oncoprotein latent membrane protein 1 (LMP1). J Exp Med. Apr 16 2001;193(8):943-954.

105. Canning M, Boutell C, Parkinson J, Everett RD. A RING finger ubiquitin ligase is protected from autocatalyzed ubiquitination and degradation by binding to ubiquitin-specific protease USP7. J Biol Chem. Sep 10 2004;279(37):3816038168.

106. Guasparri I, Wu H, Cesarman E. The KSHV oncoprotein vFLIP contains a TRAF-interacting motif and requires TRAF2 and TRAF3 for signalling. EMBO Rep. Jan 2006;7(1):114-119.

107. Thurau M, Everett H, Tapernoux M, Tschopp J, Thome M. The TRAF3-binding site of human molluscipox virus FLIP molecule MC159 is critical for its capacity to inhibit Fas-induced apoptosis. Cell Death Differ. Jan 202006.

108. Matsuzawa S, Reed JC. Siah-1, SIP, and Ebi collaborate in a novel pathway for $\beta$ catenin degradation linked to p53 responses. Mol Cell. 2001;7:915-926.

109. Polekhina G, House CM, Traficante N, et al. The siah ubiquitin ligase component is structurally related to the TRAF family of proteins and modulates TNF- $\alpha-$ signalling. Nature Struct Biol. 2002;In press.

110. Santelli E, Leone M, Li C, et al. Structural analysis of Siah1-Siah-interacting protein interactions and insights into the assembly of an E3 ligase multiprotein complex. J Biol Chem. Oct 7 2005;280(40):34278-34287.

111. Habelhah H, Frew IJ, Laine A, et al. Stress-induced decrease in TRAF2 stability is mediated by Siah2. Embo J. Nov 1 2002;21(21):5756-5765.

112. Jaroszewski L, Rychlewski B, Zhang B, Godzik A. Fold prediction by a hierarchy of sequence and threading methods. Protein Science. 1998;7:1431-1440.

113. Sali A, Blundell TL. Comparative protein modelling by satisfaction of spatial restraints. J. Mol. Biol. 1993;234:779-815.

114. Marchler-Bauer A, Bryant SH. CD-Search: protein domain annotations on the fly. Nucleic Acids Res. Jul 1 2004;32(Web Server issue):W327-331. 
115. Marchler-Bauer A, Anderson JB, Cherukuri PF, et al. CDD: a Conserved Domain Database for protein classification. Nucleic Acids Res. Jan 1 2005;33(Database issue):D192-196.

116. Geer LY, Domrachev M, Lipman DJ, Bryant SH. CDART: protein homology by domain architecture. Genome Res. Oct 2002;12(10):1619-1623.

117. Hershko A, Ciechanover A. The ubiquitin system. Annu Rev Biochem. 1998;67:425-479.

118. Hochstrasser M. Evolution and function of ubiquitin-like protein-conjugation systems. Nat Cell Biol. Aug 2000;2(8):E153-157.

119. Edgar RC. MUSCLE: multiple sequence alignment with high accuracy and high throughput. Nucleic Acids Res. 2004;32(5):1792-1797.

120. Edgar RC. MUSCLE: a multiple sequence alignment method with reduced time and space complexity. BMC Bioinformatics. Aug 19 2004;5:113.

121. Eddy SR. Where did the BLOSUM62 alignment score matrix come from? Nat Biotechnol. Aug 2004;22(8):1035-1036. 
Fig. 1

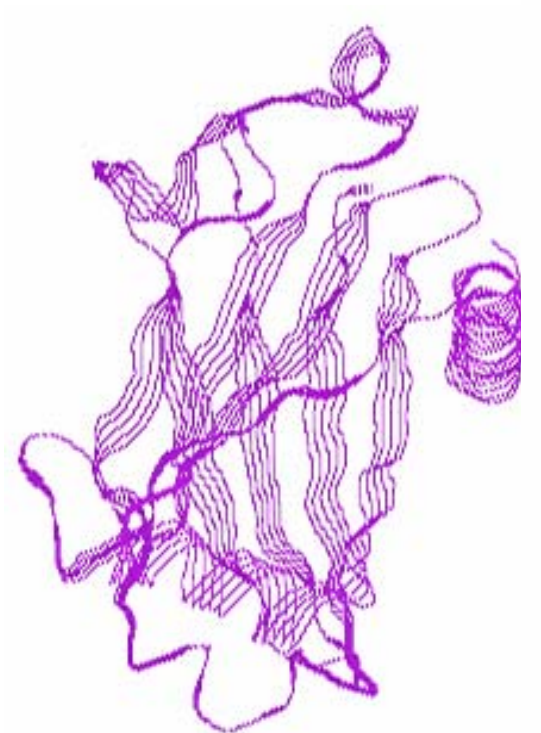

TRAF2

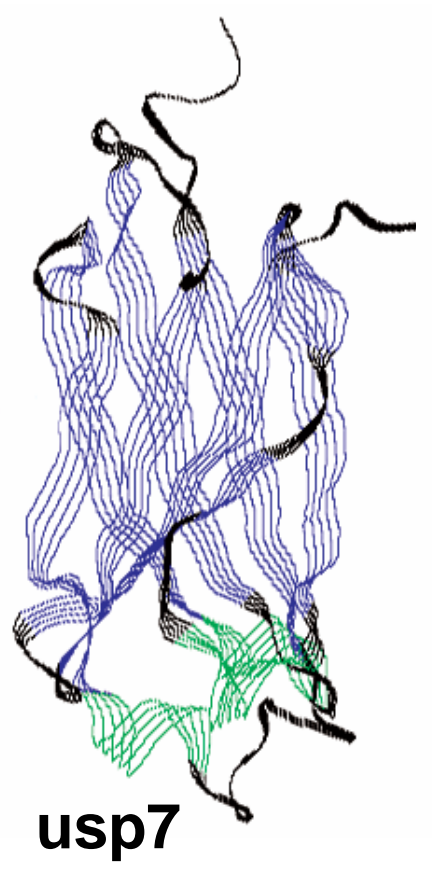

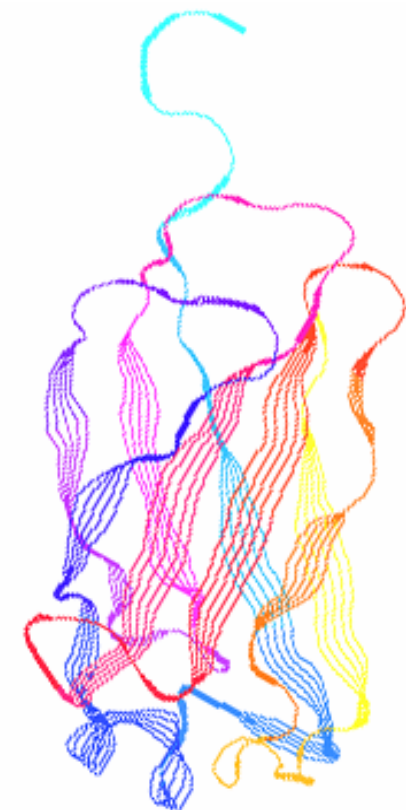

Dictyostelium

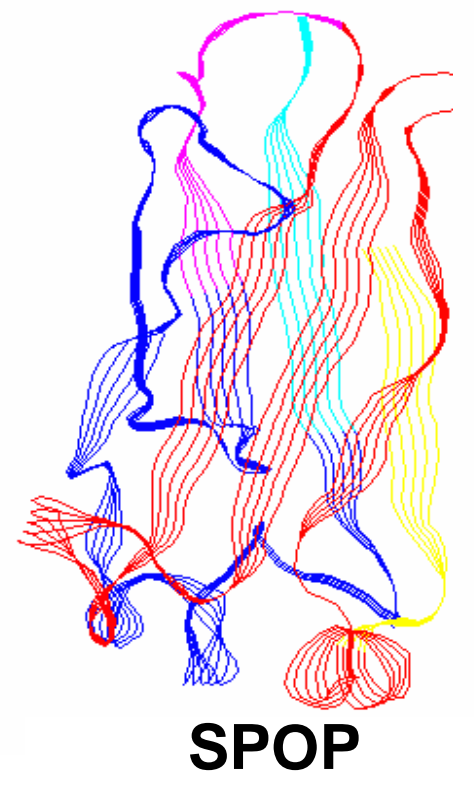

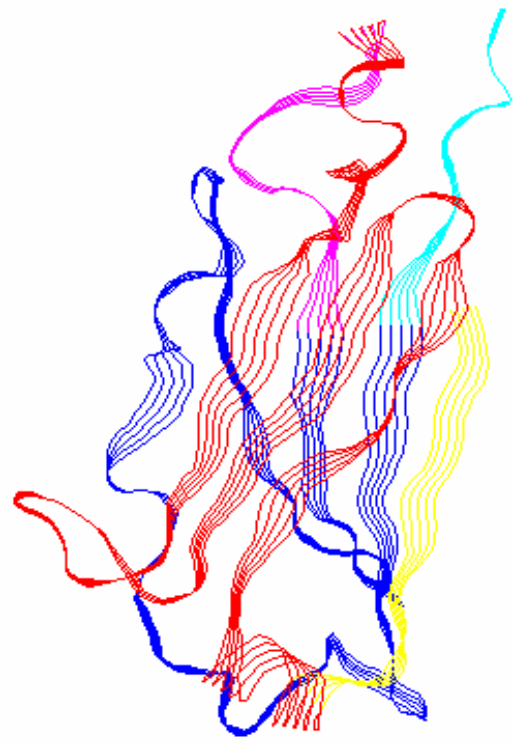

Arabidopsis

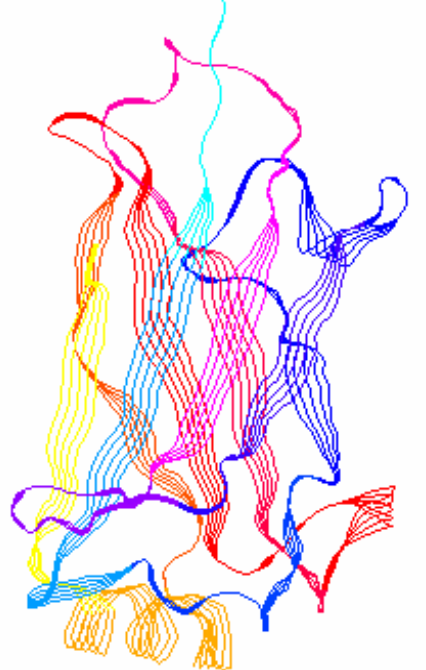

C.elegans Drosophila
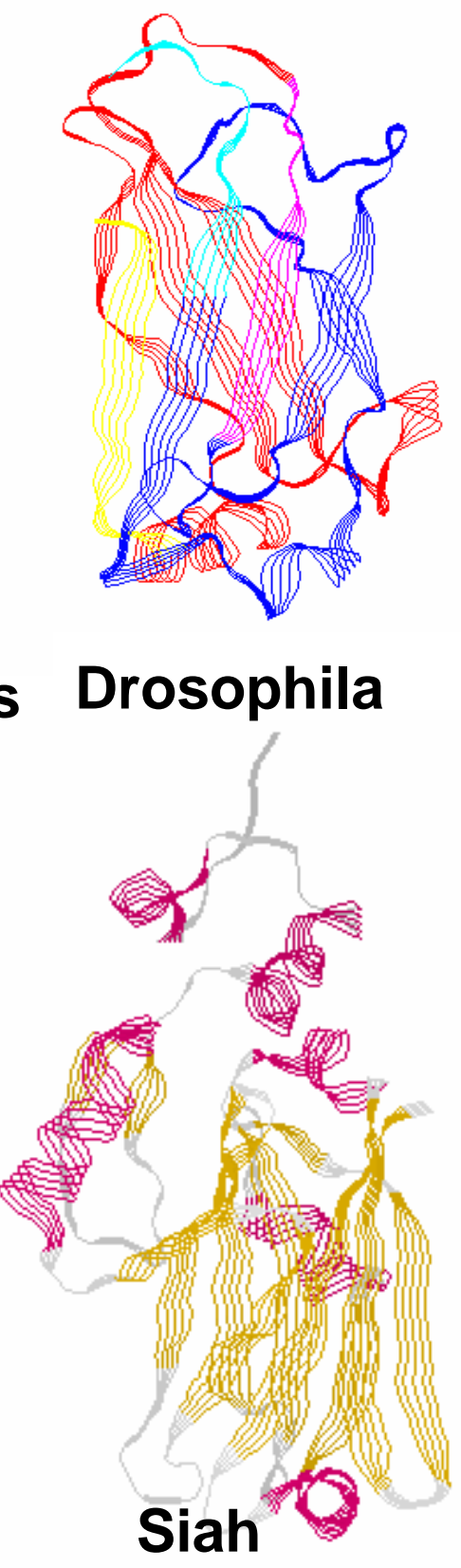
Fig. 2

A USP7 family

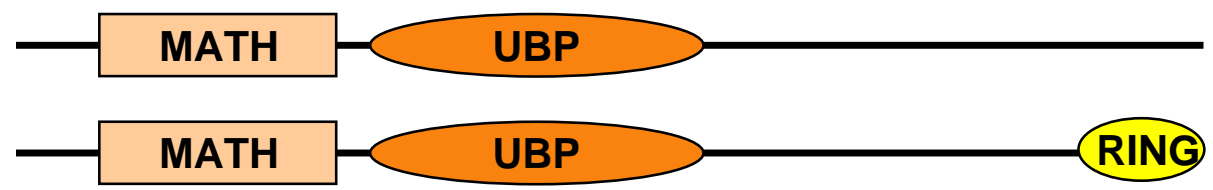

B MATHd/RIUA MATH

C MATHd-only proteins

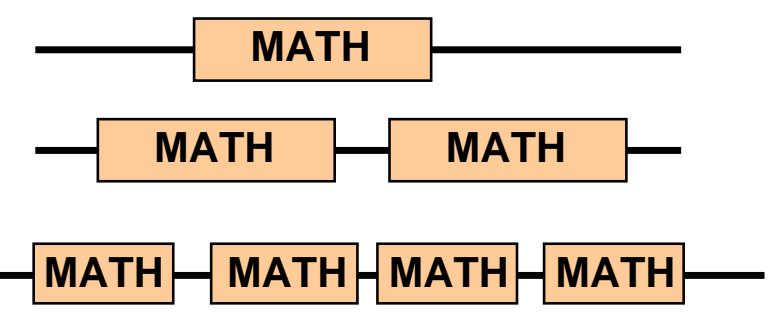

D MATHd/BTB family

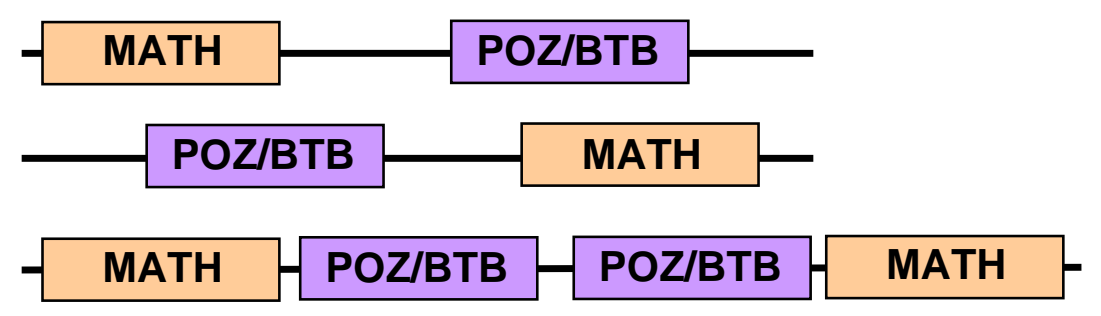

E MATHd/Filament protein
F TRAF family

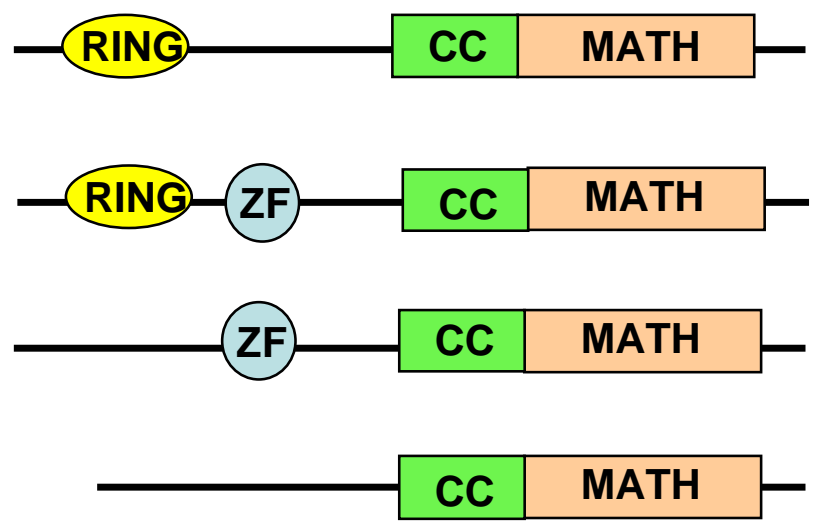

G TRIM37 family

-RING ZF-BOX BBC MATH

H Meprin family

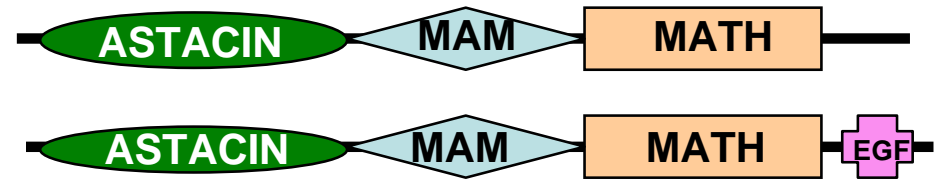

MATH MATH MATH MATH

FILAMENT 
Fig. 3

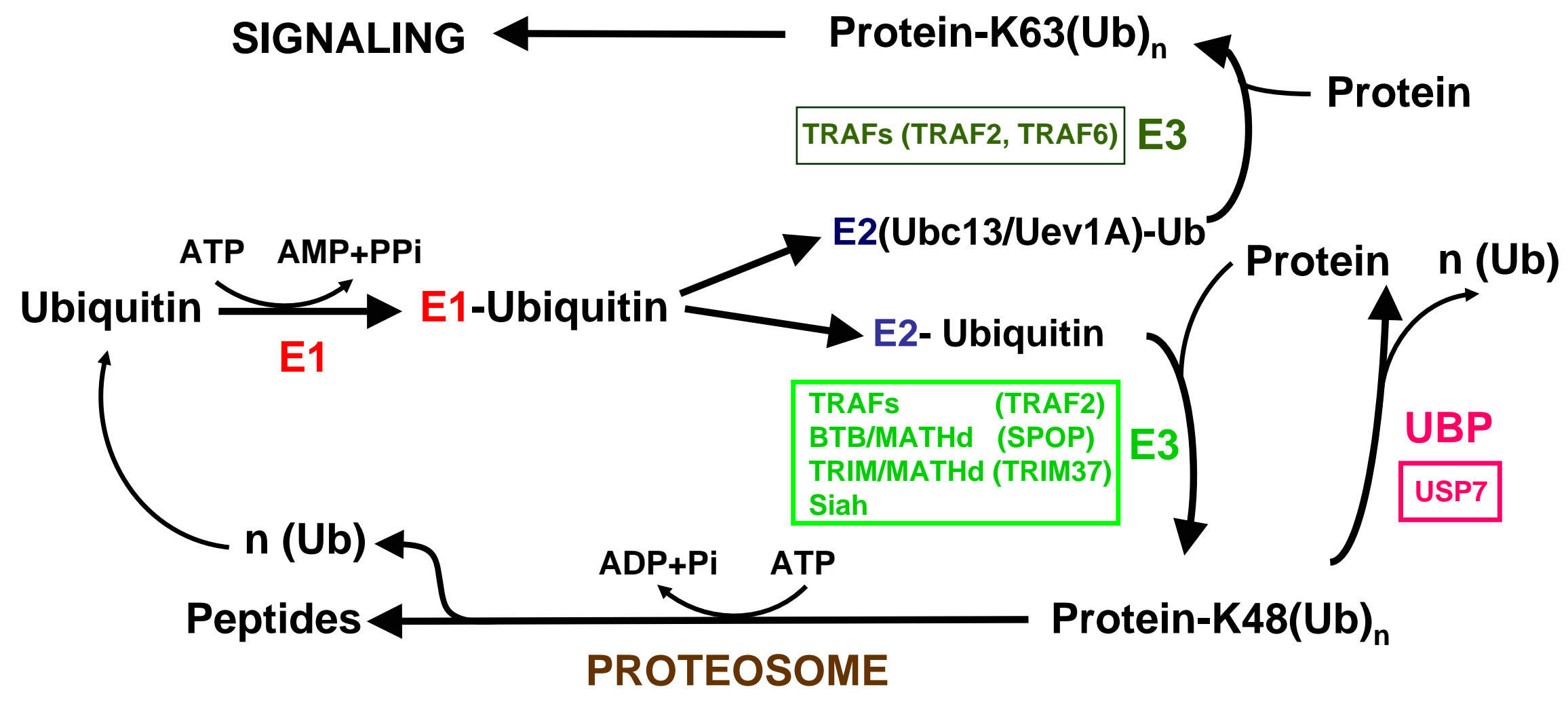

Protein

Metalloproteases

Peptides

MEPRINS 
Fig. 4

CELLULAR ORGANISMS

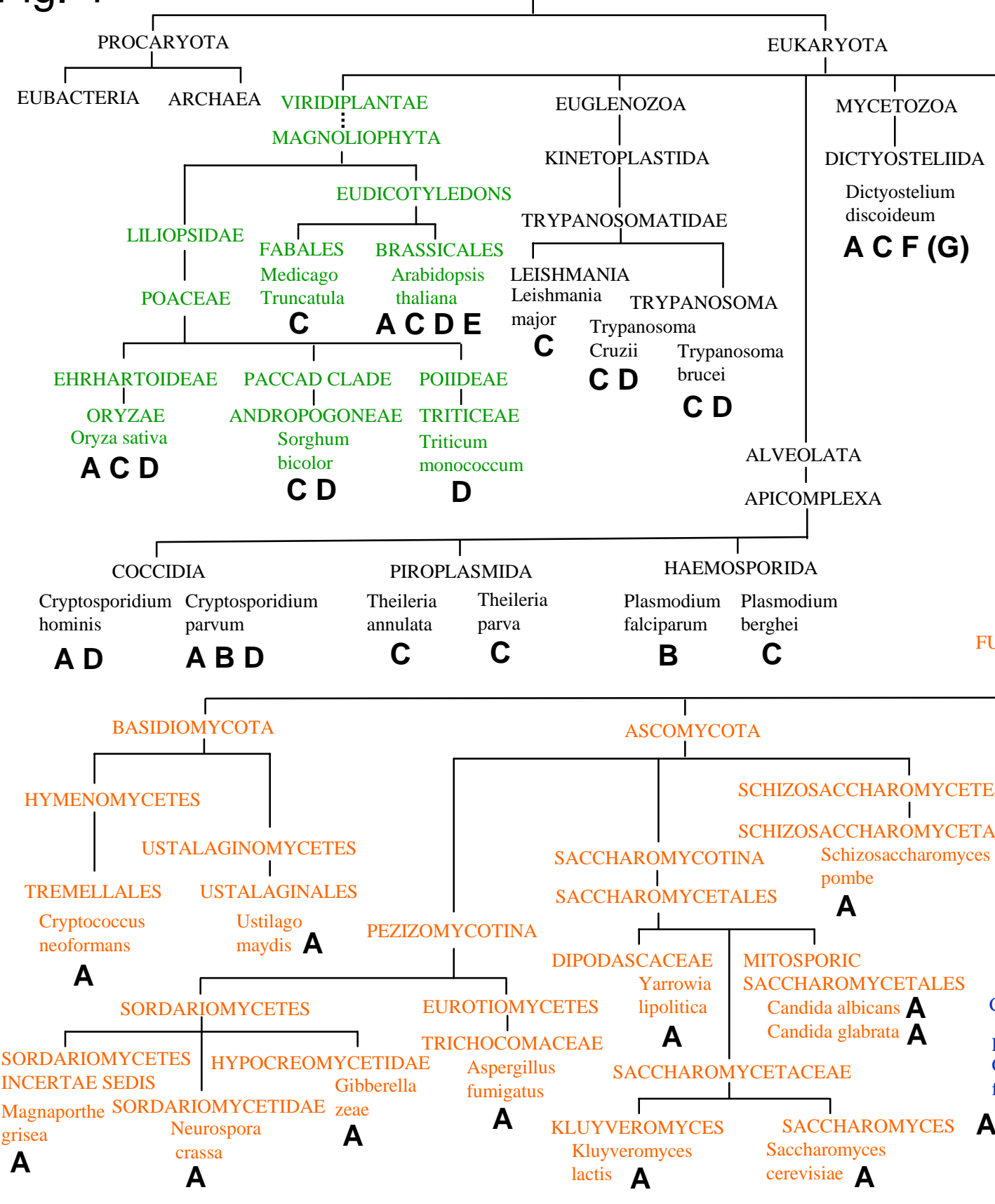

VIRUSES
IRIDOVIRUS $\left[\begin{array}{l}\text { Orange-spotted grouper iridovirus } \mathbf{F} \\ \text { Infectious spleen and kidney necrosis virus } \\ \text { Red sea bream iridovirus } \mathbf{F}\end{array}\right.$

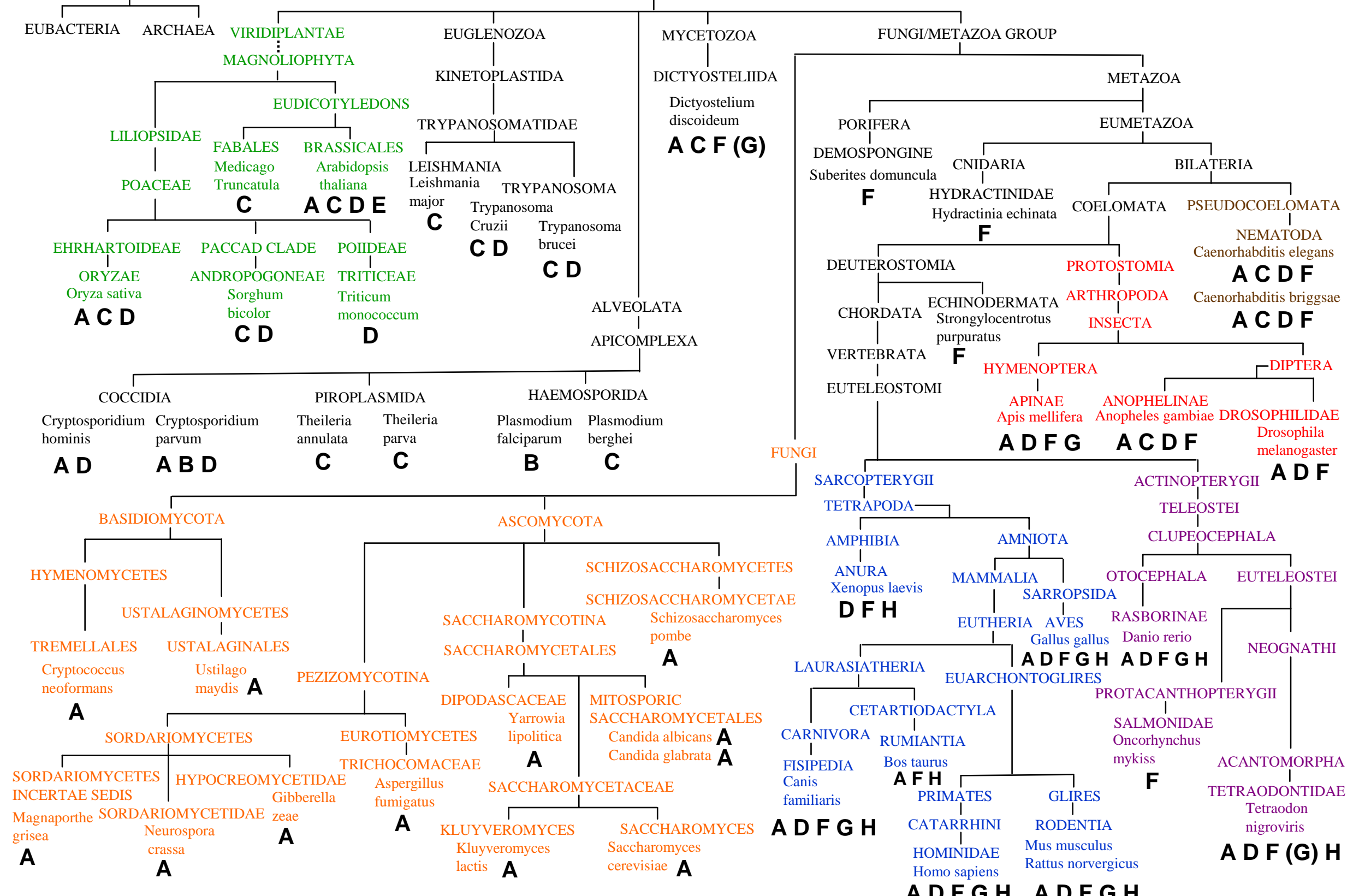




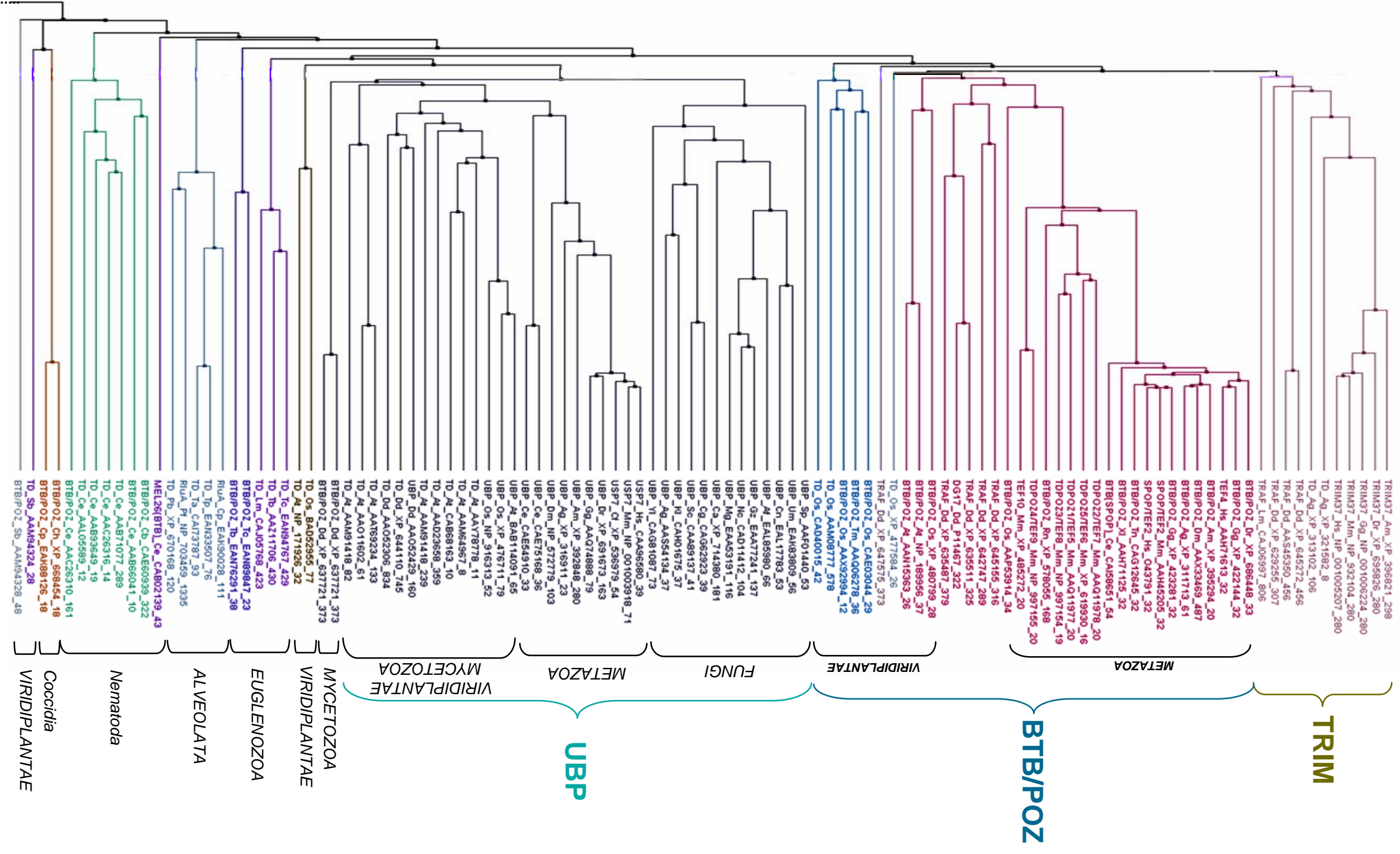

Figure 5 


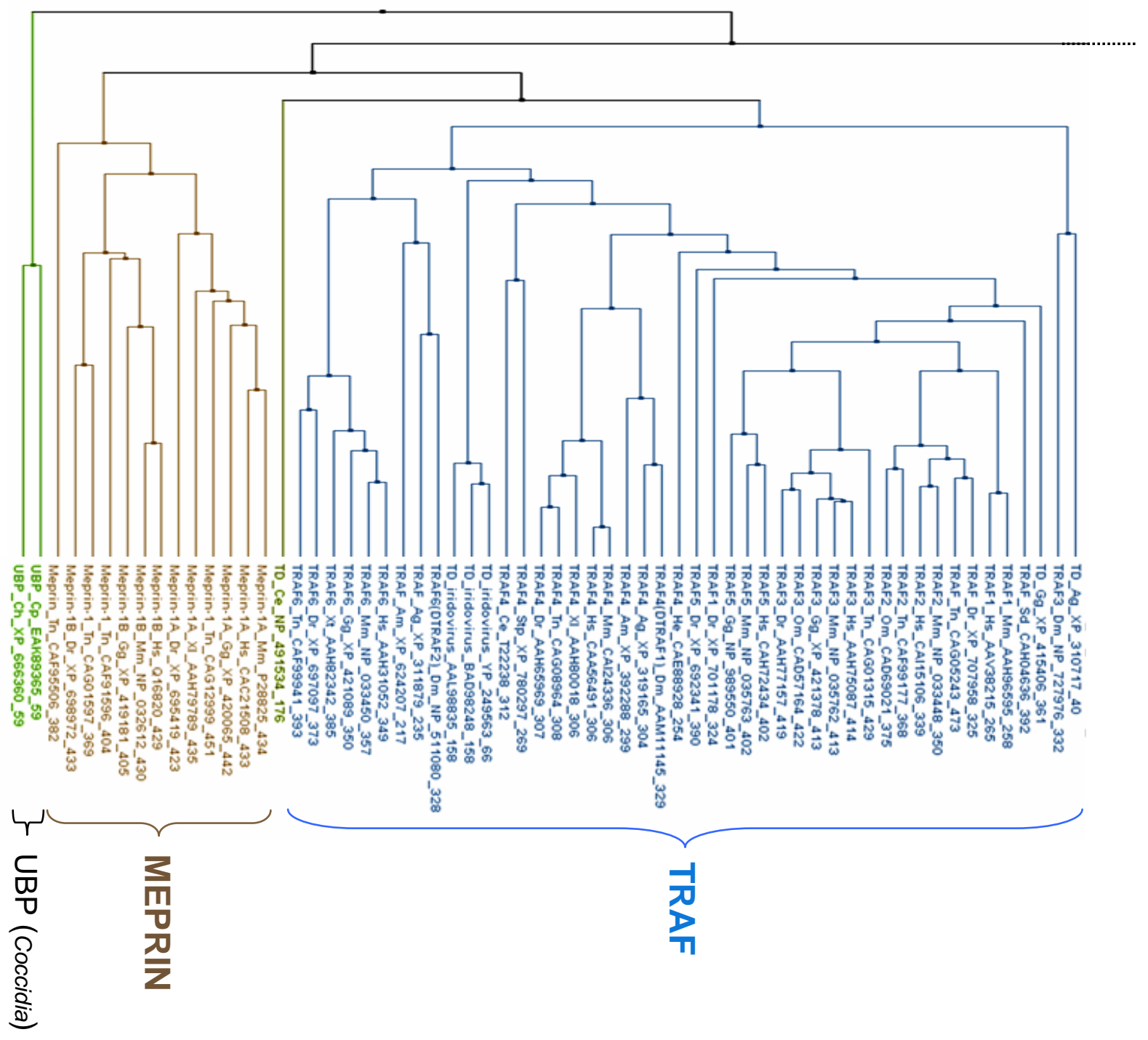

Figure 5, cont 


\section{Fig.6}

UBP_SP_AAF01440_53/1-152 UBP_Un_EAK83809-56/1-134 UBP Cn_EAL17783_53/1-131 UBP_Af_EAL85980_66/1-127 UBP_GZ_EAA77241 137/1-128 UBP_Nc_CAD11412-104/1-129 UBP AEY EAA53191 1161-129 UBP_Ca_XP 714380 181/1-134 UBP_CG_CAG62923_39/1-139 UBP SC CAAB9137-41/1-139 UBP_KI_CAH01675_37/1-135 UBP_Ag_AAS54134_37/1-128 UBP_V_CAG81087_73/1-129 USP7_HS_CAA96580_39/1-126 USP7_Mm_NP_001003918_71/1-12 USP7_C_XP_536979_54/1-129 UBP_Dr $X P_{-} 691673-163 / 1-12$ UBP_Gg_AAQ74888_79/1-135 UBP_Am_XP_392848_280/1-12 UBP $P_{-} A g_{-} X P_{-} 316911{ }_{2} 23 / 1-127$ UBP_Am_NP_572779_103/1-12 UBP_Ce_CAE75168_36/1-134 UBP_Ce_CAE54910_33/1-140 UBP_At_BAB114091_65/1-128 UBP_OS_XP_476711_79/1-124 UBP_OS_NP_916313 52/1-122 TD_At_AAY78778_11/1-134 TD_At_AAM64967_8/1-114 TD_At_CAB68163_10/1-115 TD_At_AAD23658_359/1-135 TD_At_AAM91418 239/1-121 UBP_Dd_AAO52429_160/1-121 $T D_{-} D d_{-} X P_{-} 644110 \quad 745 / 1-122$ TD_Dd_AAO52306 834/1-119 TD_At_AAT69234_133/1-129 TD_At_AAO11602_61/1-131 TD_At_AAM 91418 8 82/1-135 UBP_Ch_XP_666360 59/1-134
DSYSWVVKNFST
DFAVCTWKI KGWRT - TWR I EHWSO HTWH I QDWR YTWTVDNWRS VYTWEIKGWRN YNTWTVENWR YVWE I KDWA SF TWR I D KWS SF TWN I PDWNE. SF TWRI DNWYE. . TFQF TVERFS SEATFQFTVERFSR. EATFPFVVERFS ATFQF TVERFN TFRYTVENLS TFSYVITKFSR. TFSF TVENVVQ. .... IERFSSF . LKSQR - HLSLDI DCF SKFMSRSDNR

PTLKF TWT I PNF SR.... QNTRK

RF TWT I ENLSR... V.VTKK .

RF TWT I EDFSN ...... HRKL

KF VWVIKNFSS.... LQLQD.

KF SWVIKNFSS.... LQSEK

KF SWR I ENF TSLVDLLEKRK

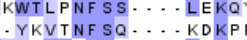
SFSYNIERFST . . . LDKNF THSYRVPNISK. . KLDAFV .. ILT I TSF SVI KGRGEPYE. TYCLKIESF I KFATSPNAEK NRL
$30 \quad 40, \quad 50$

Y. - SPLFKAGHT TWR I VLFPKGCNQ...
. . GPEFECGGHRWR I LLFPFGNSN .

. GPEFECGGHRWR ILLFPFGNS
. GPEFSCGGHKWRILLFPQGNAN

. . GPIFQCGGFPWRVLFFPYGNHV.

. GPVFQAGGF PWR I LLFPHGNN

- GPIFHAGGF PWR ILLFPYGNN

.

SPRSQVGEYQWDVLLFPHGNHN.
SPRFRIGDFEWDILLFPQGNHN. H SGKYKF DGLEWDLLIFPQGNHS. Y.SPRVQVGRWEWDLLVFPHGNS SDPF VHNGVRYRLLLFPQGKSO SPPCF VRNLPWK I MVMPRFYPD. SPPCF VRNLPWK IMVMPRFYPD. SPPCF VRNLPWK IMVMPRFYPD. - SPPCFVRNLPWK IMVMPRFYPD. SPPCF VRNLPWK I MVMPRLYPD.

SPPCYVRNLPWKIMVMPRSSQT
SPPVYVRNLPWKILAMPRNNDN.

. SPPVYVRNLPWKI LAMPRNNDN .

.. SPPVYVRMLPWR IMVIPNDRA.

. . SKPVIVRG I PWR I LA I CRHQQNNROVAT ......... LGFF LQC.

M.. SKP I I VRG I PWR I LA I CRNQQGSRHSMNSRVNRSNFNFGFFLQC

HY. SDVFVVGGYKWR I L I FPKGNNV.

Y. SE I FVVGGYKWR I L I FPRGNNV.
Y. SDVFVVGGHKWRVLVFPTGNSV.

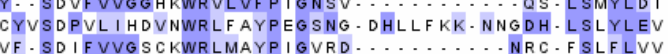

VF. SD IFVVGSCKWRLMAYPIGVRD
IY.SDQFVIDGCRWRLLAFPKGNDT

LYIKSKRFQIGNRDCRLI IVYPRGQSO. - SDKFVIGGRSWALKVYPSGDGE. TETQTILDLTWRLYVFPKGNNT. - SPVFKLYNTDWRFYIFPRGNSA SPVFRCCEKQWAIKVHPCGQPI. SSVFEAGGYKWRLVLYVNGNQN SSVFEAAGYKWRL VLYVNGNKN
E. SRPFESGGYNWTL I VYPKGN I K. SN I HSYKNFNFR IMILPKVKLT

D. GGNDH. I SLYAR .
60

ASVFLEYL'PQCKV'

. VSVYLDY.

-DY. ASFYLEH
- DSF

DQ.CSIYLEH.

SN. VA I YLEH

Ko.

O VAVYLEPHPEEKLDE

RG. VS I YLAP.

GE - VSLFLEA.

R. PHQKS.VVGFLQC.

RPHQKSVGFFLQC
RPHQKSVGFFLQC

R. PHQKS. VGFFLQC.

. PHQKS.VGFFLQC.

DR - APQKS - LGFF LQC
SV-SPAKG - LGFFLQC

VNRSNFNF GFFLQC.
D.

KSDH. LSLYLDV
PPSH.LSIFLEV.

GQGNS. LSLYVVA.

DNKD. I SLFLDL

SGF. F SLYLDY

D. GGNNH. I SLYVR I.

EG.APLNY. VSMYVQ

SGG. SLEGH. I SAYLEA.
90

100

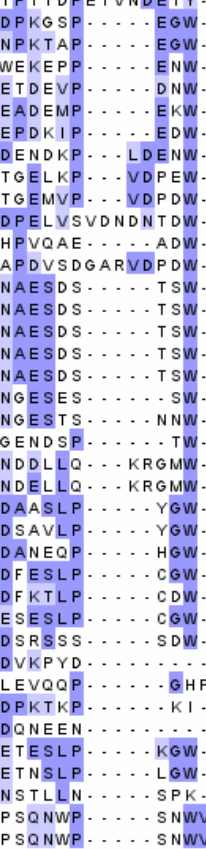

Conservation

Quality
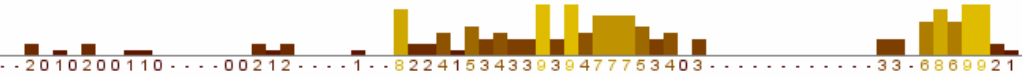

-

Consensu

UBP $S P_{-} A A F 01440 \_53 / 1-152$ UBP_Un_EAK83809_56/1-134 UBP_Cn_EAL17783_53/1-131 UBP_Af_EAL85980_66/1-127 UBP_Gz_EAA77241_137/1-128 BBP_N_CAD11412-104/1-129 UBP_ME_EAA53191_116/1-129 UBP $P_{-} C_{-} C A G 62923 P_{-} 39 / 1-139$ UBP-C UBP_SC_CAAB9137-41/1-139

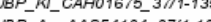
UBP_AG_AAS54134-37/1-128 UBP - I CAGB1087-73/1-129 USP7_Mm_NP_001003918_71/11-12 USP7_CF XP 536979 54/1-129 UBP_Dr_XP_691673-163/1-128 UBP_Gg_AAQ74888_79/1-135 UBP $P_{-} A m_{-} X P_{-} 392848_{-} 280 / 1-127$ UBP_Ag_XP_316911_23/1-127 UBP_Dm_NP_572779-103/1-120 UBP_Ce_CAE75168_36/1-134 UBP_Ce_CAE54910_33/1-140 UBP_At_BAB 114091_65/1-128 UBP_OS_XP_476711_79/1-124 UBP_OS_NP_916313_52/1-122 TD_At_AAY78778_11/1-134 TD_At_AAM64967_8/1-114 TD_At_CAB68163_10/1-115 TD_At_AAD23658_359/1-135 TD_At_AAM91418_239/1-121 UBP_Dd_AAO52429_160/1-12 $T D_{-} D D_{-} X P_{-} 644110-745 / 1-122$ TD_Dd_AAO52306_834/1-118 TD_At_AAT69234_133/1-129 TD_At_AAO11602_61/1-131 TD_At_AAN991418_82/1-135 UBP_CP_EAK89365_59/1-134
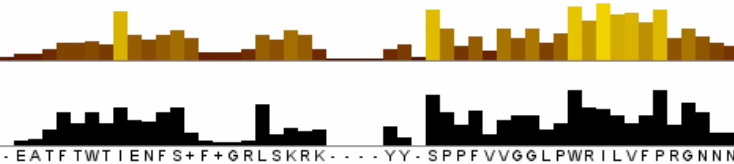

\section{-EVYAEVKFF I YNRKE}

110

- SCCAQFALSL'SNVQD

HVCAQFALVISNPQD

HACAQFCLA ISNPWD

YACVQFALVLWNVND.

SCVVGALVLWNPN

SCCVQFALVLWNPND.

VCAQFGLD IWNPAH

CCAQFA I ALSRPDD

CCAQFAIOISRPON.

VVAOFA IVLSRPGD.

AVCVOF SLVMWWPNA.

SCHAQAVLKI INYRD.

SCHAQAVLKI INYRD.

CHAQAMLKI I NYKD.

SCHAQAVLKI INYKD.

CSASAELRLLKADR.

CNA I AELRLKCHKP

YYQQATLELNANG

RYATVLEVLNADG

RYAQF SLSVVNQMH

KYAQF SLAVINQLD.

KRHTRLRLNVVNQLS.

RHAQFSFT I VNH I .

SCFVSHRLSVVNQRS.

KIYLKAKLRI INQRD

PNI KASFTLEILNQKN

RY I CF I LEVVNKDS
. VLFSLELVSQTY

EVNVELKLFVYNGKQ

.

WL NTRYSVTL INQKDYRK
140

- Ṕ. Vime

150
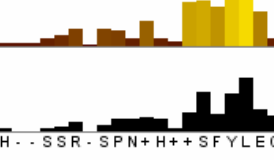

170

180

190

200

作 PT - IOTSSHAHHRFVAEE. CDWGFTRFVDLRKLYTADPANGKNRPTI. ENDEVEITAFV

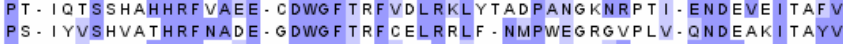
PS. TYSHVATHRF NADE. GDWGF TRF CELRRLF. NMPWEGRGVPLV. QNDEAKI TAYV
PS. LYIHHTAHHRF TKEE. GDWGFTRFVEHRRMF. NVPWEGSSRPLC. ENDTANITAYV PS. LYIHHTAHHRF TKEE. GDWGF TRF VEHRRMF. NVPWEGSSRPLC. ENDTAN I TAYV
PS. VFHHHSAHHRFTKEE. SDWGFTRF LELRRLF. SQPYDGSSRPLG. ENESVN ISAYV PS. VFHHHSAHHRF TKEE. SDWGF TRFLELRRLF - SQPYDGSSRPLG. ENESVN I SAYV
PS. IYAHHTAHHRFTKDE. GDWGF TRFQELSKLF. NVPYDDATRPL I. EDETAN I TAYY PS. IYAHHTAHHRF TKDE. GDWGF TRFQELSKLF- NVPYDDATRPLI- EDETANITAYV
PD. AHLPNQSHHRFTKNE. TDWGF SSLIELRQLE. Q-VNNPRNQSSM. YAILENNKLN I PD. AHLPNQSHHRF TKNE. TDWGFSSL I ELRQLE. Q- VNNPRNQSSM. YAILENNKLNI DQE I NLVNKSNHRF NSLD. TDWGF ANFVDLGSLK. YPSKGRNRGFL. NDDKLNI TVFV GDT I NLINKSHHRFNALD. TDWGFANL I DLNNLK. HPSKGRPLSFL. NEGTLN I TAYV DANVQLSNKASHRFTATD- KDWGF SNF I EVDYLK. HYSRNKPSGFL. NQGAVN ISVF I DARTQLVSRSQHRFNAVD. KDWGF SNL IELEHLR. . FATRGRPSGFL. SGDQLNVTVYV PY. IFQNMVAHHRFDAEDGGDWGF SRFYDLRRLA.-ARHL DE. KSFSRR I SHLFFHKE. NDWGF SNFMAWSEV DD-KSFSRR I SHLFFHEE. NDWGF SNFMAWSEVT . DE. KSFSRR I SHLFFHKE. NDWGF SNFMAWSEV DE. KSFSRR I SHLFFHKE. NDWGF SNFMSWSDVT DE- KSFSRR I SHLFFHKE. NDWGF SNFMAWSEV GQ-EPFSRKIQHLFYSKE. NDWGFSHFMTWQDVL. - SA.EPFIRRIRHTF CMEE. NDWGFSSFMNWQEIL. DAQPF TRAR I KHLFYSKE. NDYGYSNF I TWQELK. PPIQKKIHHSFHNTE. VDWGF SNYDQYDTLT - PSIQKKIHHSFHNTE. VDWGF SNYDQYDTLC. TR. YTVRKETQHQFNARE. SDWGF TSFMPLSELY. NK. F T IRKETQHQF SARE. SDWGF TSFMPLGDLY. SK- YSLRKEAAHHF STRE- SDWGFT SFMHLGDL EH. SSVKREGRKWF DKKA. PEWGWEEMISLTKLN . EE. L S I LKE TQMWF DQKT . PAWG F LAMLPLTELK
PEKCSQRKET I HWF CEKV. SDWGF TNLVPLIELK PEKCSQRKET I HWF CEKV. SDWGF TNLVPL IELK
EE. KSVTKESQNRF SKAE. KDWGWREFVTLT SLF ..SKHMEKKVESWSDQA. NSWGFQKFVPFADL. PE. KNVRKI SDHLFNSKG - VDWGFNRFMDIQTLL. KK. SEKKYSFHTFCYSS - VNWGF KKF LPLDT IK. PD. KS I KNWVQYLFNSKN. LSFGYPKF I I IF SLF. RKYLIVKDG I VKRYNDAK. KEWGYGKL IPLTTFL. HKYLTVTDGLVKRYNNAK- KEWGFGQLIPRSTFY DPEKGF I. DDDKVTFEVFV
DPEKGF I. DDDKVTFEVFV DPEKGF I. DDDKVTFEVFV
DPEKGF I. DDDKVTFEVFV DPEKGFI. DDDKVTFEVFV
DPERGFV.EDDKVTFEVYV DPERGFV. EDDKVTFEVYV
DPEKGF I. EEDKVTFEVYV DPDKGF I. KDDS I TLEVHV DPDKGF I-KDDS ITLENI TLEVYV DSEKSYV. HNNS I TLEVHV SPKDGYV. I DDVIRLRCRF NPKDGYV-VNDT I KLRCRF DPSRGYL. VNDTVLVEAEV NPSRGYL. VNDTCI VEAEV DPTKGYI-VNDKCI IEAEV DINSGFV-VNGELMIVAEV 
TRM37_Am_XP_396821_298/1-121 TRMM37_Dr_XP_695826_280/1-124 TRMM37_Gg_NP_001006224_280/1-124 TRMM37_Mm_NP_932104_280/1-124 TRMM37_Ho_NP_001005207_280/1-124 $T D_{-} A g_{-} X P_{-} 321582 \_81-120$

TD_Ag_XP_313102_106/1-108 TRAF_Dd_XP_645272_456/1-123 TRAF_Dd_AAS45350_4561-123 TRAF_Dd_XP_629255_307/1-116 TRAF_Lm_CAN06997_806/1-113 BTB/POZ_D $C_{-} X P_{-} 686448$ 33/1-129 $B T B / P O Z Z_{-} g_{-} X \bar{P}_{-} 422144+32 / 1-130$ TEF4_HS_AAH71613_32/1-130 BTB/POZ_Am_XP_395294_20/1-130 BTB/POZ_Dn_AAX33469_487/1-130 $B T B / P O Z_{-} A g_{-} X P_{-} 311713-61 / 1-130$ BTB/POZ Gg XP_423281_32/1-130 SPOP/TEF2_Nm_AAH45205_32/1-130 SPOP/TEF2_HS_O43791_32/1-130 BTB/POZ_Tn_CAG12645_32/1-130 BTB/POZ_XI_AAH71125_32/1-130 $B T B(S P O P)$ Ce_CA/58651_54/1-130 TDPOZ2/TEF7_Mm_AAQ11978_20/1-130 TDPOZ5/TEF6_Mm_XP_619930_16/1-130 TDPOZ1/TEF5_Mn_AAQ11977_20/1-130 TDPOZ3TEF8_Mm_NP_997154_19/1-132 BTB/POZ_Rn_XP_578055_168/1-128 TDPOZ4/TEF9_Mm_NP_997155_20/1-130 TEF10_Mm_XP_485272_20/1-130 BTB/POZ_OS_AAP53914_34/1-132 TRAF_Dd_XP_645155_316/1-122 TRAF_Dd_XP_642747_289/1-123 TRAF_Dd_XP_635511_325/1-124 DG17_Dd_P11467_322/1-125 TRAF_Dd_XP_635487_379/1-121 BTB/POZ_Os_XP_480799_28/1-136 BTB/POZ_At_NP_189956_37/1-133 BTB/POZ_At_AAN15363_26/1-133 TD_Os_XP_477584_26/1-133 TRAF_Dd_XP_647575_373/1-116 BTB/POZ_OS_CAE03044_29/1-123 $B T B / P O Z$ T $m_{m}$ AAQ06278_36/1-128 BTB/POZ_OS_AAX92994_12/1-129 TD_OS_AAM08777_578/1-147 TD_OS_CAD40015_42/1-131 BTB/POZ_Dd_XP_637721_373/1-126 BTB/POZ_Dd_XP_637721_373/1-126 TD_OS_BAD52955_77/1-121 TD_TO_EAN94767_429/1-106 TD_TD_AAZ11706_430/1-116 TD_Lm_CAN05768_423/1-115 BTB/POZ_TC_EAN89847_23/1-121 BTB/POZ_TD_EAN76291_38/1-122 RluA_CO_EAK90028_111/1-125 TD_TP_EAN33507_76/1-121 TD_Ta_CA/73787_93/1-124 RIUA_Pf_NP_703459_1335/1-124 $T D_{-} P_{B} X P_{-} 670168$ 120/1-108 $M E L 26(B T B)$ _Ce_CABO2139_43/1-120 $B T B / P O Z$ Z C _ CAE60939_322/1-118 $B T B / P O Z$ Ce $A A B 66041$ 10/1-123 TD_Ce_AAB 71077_289/1-114 TD_Ce_AAC26316_14/1-111 TD_Ce_AAB93649_19/1-116 TD_Ce_AALO5589_12/1-113 BTB/POZ_Ce_AAC26310_161/1-120 BTB/POZ_Ch_XP_668454_18/1-118 BTB/POZ_CP_EAK88126_18/1-118 TD_Sb_AAM94324_28/1-113 BTB/POZ_Sb_AAM 94328 _48/1-119

$20 \quad 30 \quad 40,50$

$\cdots$. . . TFV. LENFS. . . . . LRQRAD... PVYSPPLQVS.GL .

- TFV.LENFS. . . . . LRQRAD. . . PVYSPPLQVS. GL .

- TFV. LENFS. . . . . LRQRAD.... PVYSPPLQVS. GL

- TKTYT. LRNFS. . E . . MQRKDS . . F IYSDPLVDDLGF

$\ldots \ldots$ IKSSN....................

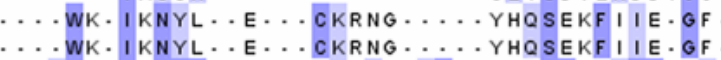

VWD. I KNFS.

RF VWV - I T DMA.

MA....... SRQA....

SSYMWT. INNFS. . F . . . CREEMGE
F SYMWT. INNFS. . F . . C CREEMGE

F SYMWT. INNFS . F. . C CREEMGE

F SYMWT. INNF S . F . . CREEMGE

F SYMWT - INNF S. . . . CREEMGE

F SYMWT. INNFS . F . . CREEMGE

F SYMWT. I NNFS

F SYMWT. INNFS. . F. . CREEMGE

F SYMWT. INNF S. . . . CREEMGE

F SYMWT. I NNF S . F . . CREEMGE

F SYMWT. INNFS. . . . CREETGE

F NYMWT - I NNF S.

F CYEWT. I SNF S.

CYKWT. ISNF S.
CYKWT. ISNF S

CYNWT. ISNFS

- YEWA. I RNF S.

\begin{tabular}{l|l} 
LCYSWT. I SNFS. \\
LCYRWT. I SNFS.
\end{tabular}

CYRWT. I SNFS. - H F
.

WV. I TNWS. . Q

KGNWT. I ENWS..Q.

WI. ISNYS..S.
$W 1$. ISNYS. .

WI. I SNYS. .

THVFT. IHGYSLQA.
. SHQFV. IQGYS....

SHQFV. IQGYS.

. HLLK. ISGYS.

KNRWS. I SNYL. . T . .

K. IDGYS. . R.

SHLVR. I DGYS

HHVFR - IRDYS. - L . . LEAITPNGK. SI IKSTSFAVG. GH

VLTMH - I DSYK. . E. . ATKLAANGM-NIKSPNLDAG.GH.

- SWP. I HNFS..... I KSQ..... KHVSNCFEMY.GL

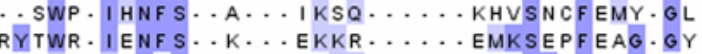

. ITFQ.VENVS. . I . . LPKDNE. . . RRYSPEFEFG. KL .

I TFQ - VENIS - L . . L LPKDSE . . . RRYSPEFEFG. QM .

- TFH. VNN IS. - M . . LTKESE. . . RHYSPEFHFA. NL. VKLLR. . . . MSLDA..... SHYSPQFTVG. GY.

CWRLKVYPDG. CWRLKVYPDG CWRLKVYPDG

CWRLKVYPDG

CWRLKVYPDG

TWRLL I YANG

RWRIQIYPGO

PFFIGIFTDO

PFF IGIFTDG

SF HLWLYPNG.

PWYVGMDTTA

VVRSSTFSSG. PNDKMKWCLRVNPKG.

TFSSG.PNDKMKWCLRVNPKG

TLSTF SAG. ANDKLKWCLRVNPKO

ANDKLKWCLRVNPKO

STFSSG. ANDKLKWCLRVNPKG.

作

CMGG IRR. . KI KSPVF SLE. ANEEVAWCLRVHPNG

FMEGTRE. . KI TSPKF SLE. ASDKVEWCLRVHPNG .

CMGG IQR -..RITSPVFSSE. ENKEVAWCLRVYPKO .

CMDGILE. . . NI TSPGF SLE. ASEEVQWCLTI YPPNC

FVEETEE... YITSPVF SLE. DNDKMTWCLRVYPTO . . .

LKSNVDPSOHLLLSSPF SAC. DNDKMTWCLRVYPTC.

KLTHYPNNE. RLKSPYFCIG.SK...SFYVGLYPNG . SF YVGLYPNG
HFQVCVYPKG. LF QVCVYPKG EFVISIYPNG. DWCLRYYHNC DWT I FVYPDG DWA I YF YPDC TWR I VFYPNG KF KLVI YPQG. SWHLRYYPNG RWF I RFYPNG. SWHVEYYPNG. SWH I LVYPNG. TWKMMWAYPAG. TWKMWAYPAG

KWY I LVYPQG

KWSLL CMANK.

KWSLL CMANK.

KWSLLCMTNK

TWRLHLQRRA

LWRLHLQQRC DMESPQIGYCRG DIESPTEGSSKGF DIESPTEGNSKG

YYRLLVHPRGGSCNDSESSYLSVFLEALYH.

HYRLLLHPRGTAGTDSESSHLSVFVEAVVQ.

HYRLLLHPRGTAGTDSESSHLSVFVEAVVQ.

YYKVLVHPRG...NSNDDNYMSAYLEVIKQ. EIKSISTGNSDDF... YF KLLVHPRG... NSNEDNYISI YLEVIKQ.. DFY YLENF VYLQR. GDEQLTWS IKI YPKG. NGENNKDF. V V LCLNRVINNNV EAESEKEEHF.GR . . FWHMSLGRGG....... DYLGFF I DF SNP. IST ELYSPQEMHF . NI . . PWIMLKIKRNA....... DHLGAYCYCLKLPKDED SIF TDIQTRF. NI . . PWKLKIRKQD........ GFFELFLLCDKQ. . LCK NYYTNLEDRF - N I . . PWR I N I KKMS....... GNFEF YLRCEKE. . ECE DYCTKTEKRF - N I . . PWRLL IQRRN . . . . . GFFGLL I C CQKE. Q QSN

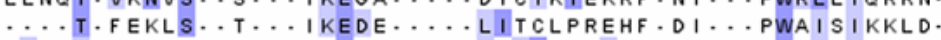
FDHS. FEKVD. . . . LAEGD. . . MRRSQPITHL. DF . . TWTIYITRKN. YIWT. IEDF PLLRTLAMQRALPNHD.RI ISEKFGDQHNG . . TWF LT IFPAG.

YIWT - IEDFPLLRTLAMQRALPNHD. RI ISKKFGDQHNG . . TWFLTIFPAG.

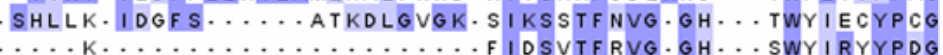
GNFYVYLCCEKE. . LGY .... QHLRVSLCCGKA...HL

60

NGVVRGNYLSVFLELSAG. NGVVRGYYLSVFLELSAG. VVRGYYLSVFLELSAG. HNEARGNHLS I YLILFEG. NAECKGQFLSIFIELCSG.

GISIYLFLDTS...D ... SPSNSLSLYLVLTKG ....

DDESKDYLSLYLLLVSC. LDDESKDYLSLYLLLVSC. DEESKDYLSLYLLLVSC. LDEESKDYLSLYLLLVSC. LDEESKDYLSLYLLLVSC DDESKDYLSLYLLLVSC. LDEESRDYLSLYLLLVQC
FDEESKDYLSVYLVLVNC. ADKESKDYLSVYLGLLHC. VDEESKDYLSVYLELLSA. VDEKNKDYVSLYLILLSC. VDEKNKDYVSLYL I LLSC.
CTEESKDF I S I YLVLEDT. NQTNAGFMS I FLHLYEK. DENKEYI SL YLRVNN I DENKEYI SLYLRVNN I. NIESDDDYI SVFLELMTK. KNPEDNSSYVSVF I VLASE.
KNPEDQSSYI SLF I ALASD. SMDHGAF SF YLKL I DR. FNSDCAECISIFLQLDYN. HGPRDVGVVSVYVGIAGAYRRGG YDADHTDYVSVFLVLEDDIAAAG EAKHSDSF SVYLEAVRV . KEK AKHSDSF SVYLEAVRV..KEK CDVSNHLSLFLCVANH. DKL EFLALYLCQTGS. ESLALYLCQTGS. VNCDGDMLS I YLFSYSE.

VNCDGDMLSI YLF SYSE.

ADEERAGWVTLFLCLSAH.

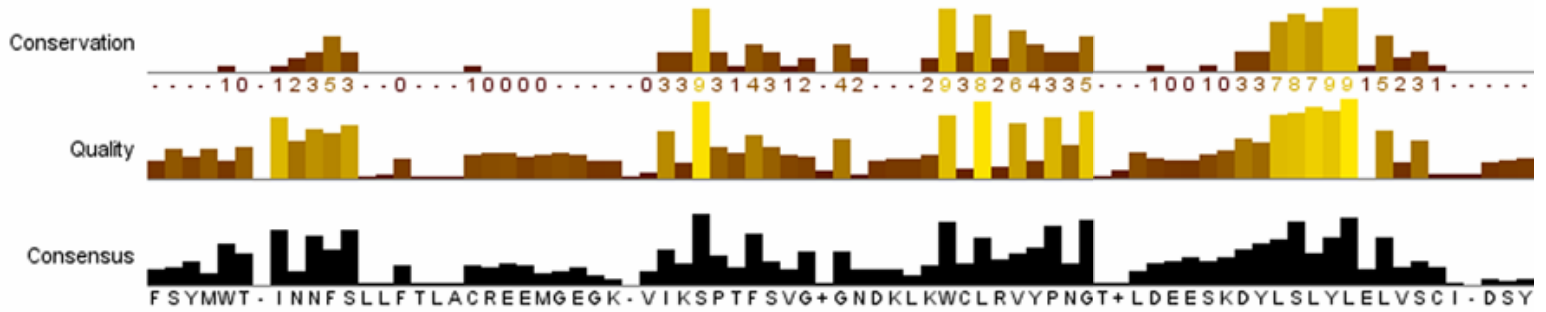


Fig. 7 (cont)

80

- LPETŚ - KYEYRV - EM I . LPETS . KYEYRV. EMV LPETS - KYEYRV - EMV - LPETS - KYEYRV - EMV . - LPETS - KYEYRV - EMV. VSARFEYRV. ELL. IANKYDFTV.AIL PKGRSI. NTEFSL. KFN PKGRSI- NTEFSL. KF N

EKT . F VNFSI. SIK EHRVDF. RVI

- PKSEV.RAKF KF. SLL PKSEV.RAKF KF. SLL PKSEV.RAKFKF. SLL. NKSEV.RAKF KF. SIL - NKSEV. RAKF KF. S IL.

NKSEV. RAKF KF. SII PKSEV.RAKF KF. S IL PKSEV.RAKF KF. S IL PKAEV. RAKF KF. SIL. PKNEV.RAKF KF. SLL NKSEV.RAKF KF. S I L PKRQV.RAKFEF.WIK. QKSPV.WAKYEF - WI I . - LQSPV.WAKF KF. WI I . LESPI. LAKFEF - WI I PKSPV. WAKVQF. WII EKGSV.WAKFEV.CIL. EKGSV.WAKFEV. CIL. I TDVV.SAQVTF. SLL. . KVQF SF. ELL. PSTSTTVVRFSF. ELL EEPNSL. KVEYSF. TLV . EEPNSL - KVEYSF - TLV. DPN - KLEFTL - ELV . DAEV.RTIFDI.RML - CTEV.RALFEL. SLV. - SNDI. RALFEL. TLM . SKGV. DAEIQF. SLL NPI. KVFYKF. VLL VMKGV.KAQYKF. SLL. TFEKPI. DVQFDF. SFV . GDAKPV. IADARF. SLV GAGEPV. NVQLRF. RFV

PDDGG. YVKFEYQFML ESYEFLRNTTFFF. GLV. ESYEFLRNTTFFF. GLV LPGWSH - FAQFTI A AVG .$$
\text { V. YCKFLI.SVI }
$$
V. HCKFLI. TVV.

AAV. VAQF KL - LLQ . QHV.VAQF KL. TLV. PDDWI F PNVRFQL. SVV PEYWVFPNVRFEL. TVV. PEYWVFPNVRFEL . TVV. PSEWVFPNVHFQL. TVH PPDWVFPNVRFQL - TVH KAGKIGFKSQFKL-RTA EQKWS I. ETEIEF. RVV GVAWTI. DGHFEL. TAL SRKWS I. ETEFQF. KI V . NRKWS I - ETEYTL - KLV RRNWT I - EVDYTL - KLL . PSNWS I. EYKST I - Q IM TSDWTV - RADF KM - TLT QIRIAQFE I. SLL QIRIAQFEI.SLL.
$100 \quad 110$

HQGSRDTS. HQASSDPT. HQSTNDPT. HQSCNDPT HQSCNDPT HPQNPT.

HQNDK. NQRDSA. NQRDSA.

NHNGND. LYHEDPARDV. NAKREET NAKREET. NAKREET. NAKREET. NAKREET. NAKGEET. NAKGEET. NAKGEET.

NAKGEET. NSKNEET NAKREET. NSQGEKY.

NSQGEKY.

NSQGEKY.

NSQGEKY.

NAQGEKY.

NAKGEKCNTER I P

DQQGNPMP..... SHTLTTPLLKF SLQGTLPKAL. . . . . . . . . . . . .

NKDFT.......RNRKLASTN IFHTENK.

HSDPT ........ KSLKFEKSNKYTENKGS.

NVLDKSK...... SITKRVDKIVF I SPKE.

NVLDKSKS.... I TKKEDKKRVF I SSEG.

NLLDKS . . . . . . KS I TRKGLEVFEE IERK.

130

140

150

160

170

GYNRF FLDLL. . ASEGYLNMQTDTLVLRYQV.

GYNRFFRLDLL.. ANEGYLNRQNDTVILRFQV.

GYNRFFRLDLL. . ANEGYLNRQNDTVILRFQV.

GYNRFFRLDLL. - ANEGYLNPQNDTVILRFQV.

GWPQFMDHERL . QEEGYLDQSADTLEFR .

GWKSFLGREEL . I INNGYI. Q QKDSLSIRLTI.

GDRRSIKTHNL. . ESNGYI. KDNTLLITAEV.

GDRRSIKTHNL - ESNGYI - KDNTLL I TAEV.

GWA . F F E KDF . KTGGYL. KNDTLSIQFTV.

GPLRF INRFTL. .EQDGFL. .VSGCLRVGIEV.

GFKKF IRRDFLLDEANGLL. PDDKLTLFCEV.

GF KKF IRRDFLLDEANGLL. PDDKLTLF CEV.

GF KKF IRRDFLLDEANGLL. .PDDKLTLF CEV.

GF KKF IRRDFLLDEANGLL. PDDKLT IF CEV.

GF KKF IRRDFLLDEANGLL. P PEDKLT IF CEV.

GF KKF IRRDFLLDEANGLL. . PEDKLT IFCEV.

GF KKF IRRDFLLDEANGLL. . PDDKLTLFCEV.

GF KKF IRRDFLLDEANGLL. P PDDKLTLF CEV.

GF KKF IRRDFLLDEANGLL. . PDDKLTLF CEV.

GFKKF IRRDFLLEEANGLL. PDDKLTLFCEV.

GF KKYIRRDFLLDEANGLL. . PDDKLTLYCEV.

GF KKF IRRDFLLDEANGLL. P PGDRLS IF CEV.

GFSKF ILRDSLLSHRNWLL. . PKDKLTLCCKV.

GF KKF ILRDFLLSNPPWLL. . PEDQLTLCCQV.

GF KKFLPRDLLLSHRNCLL. . PEDQLT I CCKV.

GFKKFLLRGLLLSHQNWFL. P PEDFT I C CKVSI

GCKNF ILRDFLLYHSHWLL. .PEDKLTLCCKV.

GFEKF I TRDSFLSPAQVLT . . PDDKF TLLCKV.

GFEKYITRDSFLSPAQVLT. . PDDKF TLLCKV.

GYNSF IRRDDL. . ERSGHL. KDDCFAIGVHV.

W. . GWRSF INNSLV. TTQTGFV. IQNSVTLN IN I.

GFSQF IDIKMI... NNF I. I DGKLT IN I DV.

GWG KFLLSDL I. NKENGWLS. NDDKLT IE I YI.

GWG KFLLSDL I. NKENGWLS. NDDKL I IEIYI.

GWSKFLASKL I. NKKNGWLS. DDDKLT I N I YV.

GSKNF I RRSEL. . EGSVYL. . RDDRLMIEC. GYKRFFRRSLL. . ETSDYL. KDDCLKINCTV. GYKRFF KRSAL . ETSDYL. KDDCLVINCTV. GFNWF I SRDEMETLQNKYVGEDDDS I I LCCD I. GCHYF IKSTEPGKKPEVWL - KDDSLVI

GYRTYIERGLL. . ESSEYL. . RDDCLT I VCDFTV GREKF IEKDAV....ERWAKHMGNYLAIRCDI. DFGMNIKRAEL - ETSGFL. KDDGFLVRCE. GTVAFKKKEKL. . EREGL I . VEDGLA IRCD I. HGFERF VSREDL - GKRGFV. KADRFQIRCDV. G. NGL IELKLLYDKSLGYM. - DNDCVTIQLHI. G. NGL IELKLLYDKSLGYM. D DNDVTIQLHI. GWKKFMELSKI. . QDGFL. VDDVLE I I AQV. GFNTVI KFEELLNPKRGFWQEEGDSVT IEV. GF NNVARF DELLNPRKGFWHKENDS I T IEV. GFNNVI KFAELLSPDQGFVTADDDSI T IEV. GMNEF I PMWRL I QQENGF VYEDEGSGALYFDIDV GVNHFVPLRQLTGAQSEFLYRDEASNAYF I DIEV GWHKMVSHVRL. TRAAGF VD. DEGTVLIR. GWQKMISHARL. TKAAGFMD. DEGTVVIR. GWQKMISHSRL. TKAAGFMD. DEGTVVIR. GWQKM I SHSKI. NKVSGFLD. ESGGLLIKGKV. GWQKMISHSKI. NKSSGFL. - DDN DYVSYIKRDVL...FPQIM. PRDMIIVNVEI. GLRRFMRWETM . . EKKYL . MDGNLSVEVHV. GRAKF MSWNEM - . I IEDYL - INDSIT IEVAAK I GW. RFMRWNSL...EEKYI. . VVDTLT IEAHVKI GWSKCI SWKDL . . E ESDYL . VDDSI VVEAHV. GRDKL I RWDDM. . . LEKYM. . VNDSI I IEARV. GCI.MMKWKSL...EKNYI. . ADDKISVSICVKI ELGQEVEWDE I . . RDKCL. . ADGKLEVETRVRI GWEDYMRINII.......... DDTS.

GWEDYMRIDII.......... DDTS GCGSFLLCH............RRTCID GYCRF IKATDMEEAT ..... KGGGFCIRCDV.

DDGGGV. KARYKF. SLFRDAAAAGDGEAPPVLI HTRTASNYSFWSADQHR

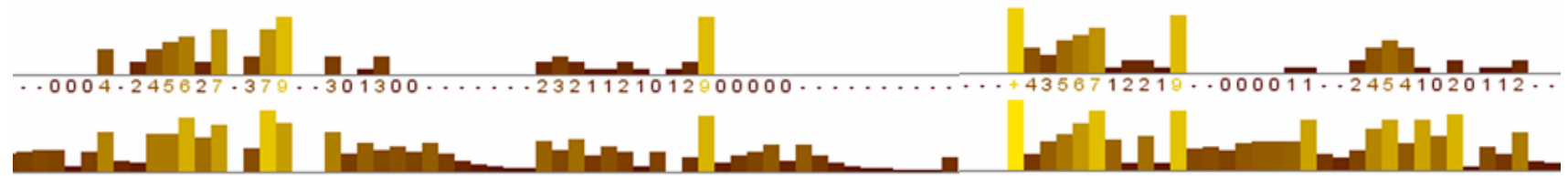




\section{Fig. 8}

TD_Ag_XP_310717_40/1-139 TRAF3_Dm_NP_727976_332/1-143 $T D_{-} G g_{-} X P_{-} 415406{ }_{-} 361 / 1-131$ TRAF_Sd_CAH04636_392/1-147 TRAF1_MNn_AAAT96595_258/1-150 TRAF1_HS_AAV 38215_265/1-150 TRAF_ Or $_{-} X P_{-} 707958_{-} 325 / 1-149$ TRAF $T n_{n} C A G 05243-473 / 1-149$
TRAF2_Mnn_NP 033448 350/1-149 TRAF2_Hs_CA/15106_339/1-149 TRAF2_Tn_CAF99177_368/1-149 TRAF2_Om_CAD69021_375/1-149 TRAF3_Tn_CAG01315_429/1-145 TRAF3_Hs_AAH75087_414/1-149 TRAF3_Mm_NP_035762_413/1-149 TRAF3_Gg_XP_421378_413/1-149 TRAF 3 Om_CAD57164_422/1-149 TRAF3_Dr_AAH77157_419/1-149 TRAF5_Hs_CAH72434_402/1-150 TRAF5_Mm_NP_035763_402/1-151 TRAF5_Gg_NP_989550_401/1-151 TRAF1_Dr_XP_701178_324/1-170 TRAF5_Dr_XP_692341_390/1-147 TRAFA(DTRAF1) Dm_AAM11145 TRAF4_Ag_XP_319165_304/1-156 TRAF4_AG_XP_319165-304/1-156 TRAFA_Am_XP_- TRAF4_Mm_CA/24336 306/1-159 TRAFA_MN_CA/24336_306/1-159 TRAF4_XI_AAH80018_306/1-159 TRAF4_Tn_CAG08964_308/1-15 TRAF4_Dr_AAH65969_307/1-158 TRAF4_Sto_XP_780297_269/1-150 TRAF4_Ce_T22238_312/1-148

TD_iridovinus_YP_249563_66/1-138 TD_irido vinus_BAD98248_158/1-138 TD_irido virus_AAL98835_158/1-136 TRAF6(DTRAF2)_Dm_NP_511080_ TRAF $A g_{-} X P_{-}$311879_235/1-147 TRAF_Am_XP_624207_217/1-143 TRAF6_Hs_AAH31052_349/11-153 TRAF6_Gg_XP_421089_350/1-153 TRAF6_Xt_AAM $823422_{-} 385 / 1-153$ TRAF6_Dr_XP_697097_373/1-150 TRAF6_Tn_CAF99941_393/1-15 TD_Ce_NP_491534 176/1-130 Meprin-1A_Mm_P28825_434/1-161 Meprin-1A_Hs_CAC21508 433/1-161 Meprin-1A_G__XP_408-4331-161 Meprin-1_Tn_CAG12999_451/1-158 Meprin-1A_XI_AAH79789_435/1-162 Meprin-1A_XI_AAA79789_435/1-162 Meprin-1A__L_XP_695419-423/1-153 Meprin-1B_Mm_NP_O32612_430/1-158 Meprin-1B_Gg_XP_419181_405/1-162 Meprin-1_Tn_CAF91596_404/1-160 Meprin-1_Tn_CAG01597_369/1-159 Meprin_Tn_CAF95506_382/1-139
$10 \quad 20 \quad 30$ NGHVMWR I DNFANRLQQSKELE. TMMKGP IRGHL I WR I KDYSKKLEESKQYD.. T ILHSAM YDGVF LWK I TDVNQKLQDSVTGR. VVSLYSPA. - NGAF LWR I PN I ARRRRDAVEER. I TSI YSPP
FDGTFLWK I TNVTKRCHESVCGR. TVSLFSPA. DG TFLWKI TNVTKRCHESVCGR. TVSLFSPA. DGTF LWK I TNVTRRCHESACGR.TVSLF SPA. YDGVF VWK I SDF SKKRQDAVAGR. APAMF SPA. FDGVF VWR I SDF AKKRQDA I AGR. APAMF SPA YDGVF IWKI SDFTRKRQEAVAGR - TPA I F SPA YDGVF I WK I SDFARKRQEAVAGR - IPA IFSPA. YDG IF VWKI SEF SRRRQEAVAGR. TPAMF SPA. FDGVF VWKI ADF SRRRQDAVAGR. TPAMF SPA . YNGTL I WKI RDYKRRKQEAVAAK. TLSLYSQP. YNGVL I WKI RDYKRRKQEAVMGK. TLSLYSOP. YNGVL IWK IRDYKRRKOEAVMGK. TLSLYSOP. YNOVL IWKIRDYKRRKQEAVIMGK. TLSLYSQP. YNG TLIUKIRDYKRRKQEAVIUK. TLSLYSQ FNGTL I WKI RDYKRRKQEAVVSK. TLSLYSQP. FNG TL I WK I RDYKRRKQEAVVSK. TLSLYSQR
YNGKL I WKVTDYKMKKREAVDGH. TVSIFSQS. YNGKL I WKVTDYKMKKREAVDGH. TVS I FSQS
YSGKL I WKVTDYRVKKREAVEGH. TVSVF SQP. YSGKL I WKVT DYRVKKREAVEGH. TVSVF SQP
YNGKL I WK I T DYKMKKKEAVEGR. VLS I F SQP. YDGTFYWR VCDVSQKQREAANSQ-KI SQYSPG YDGKL IWKVRDYWHRKESGA.......ALSSSP . NGYF I WP I KRFRQQFELARNSDEE I AVF SQP. YTGTLLWK I TDWSAKMAEARGKD - GLELVSPP YTG TLLWK I TDWSVKMQEAKTKD - GLELVSPP SDGVL I WK I GSYGRRLQEAKAKP. NLECF SPA. SDGVL I WK I GSYGRRLQEAKAKP. NLECF SPA
SDGVL I WK I GSYGRRLQEAKAKP. NLECF SPA. SEGVL IWKI I DYSRKVQEAKVRG. NYESFSPP. DEGVL I WKI SDYSRKVQEAKVRG. NYESF SPP. DGILIWKLNDYSRKLQEAKIRS. NHEFFSPP . DGVL I WKL TDYSRKLQEAKLRN- NHEFF SPP LVWK I DKYAERMQEAKQGK- KVT I F SPP. NG TL VWL VPVSSDCP....... LPMI LSPV . NG TLVWLVPVSSDCP....... LPMI LSPV NG TLVWL VAVSSDCP......... LPMVLSP SGGVLLWKLDDFSNKIESMVANS. NOMFYSSE. STVLLWKLDDF SNKIESMUAN NCMFYSS . NG I Y IWKI I NF GMHLKSQEEER. PVVI HSPG. CNG I Y I WKI IENFSGLQKAQEEER. PVVMHSPO. CSG I F I WR I NNFNSLLKNQEEER. PVVI HSQG. YQG I YVWRVENF SHHLRNQEAGQ. P I VLHSPP. CTG I Y I WRLKDF SVLLRNQEAGL . PVVEHSPG. VWT IRN I SQ I LENTKNKSHRS IYSQP . KLVSPR . . VWVVRRNFSQILENGS.... TAVIQSPR.. ...VLLHSPR . VWQVRDFSQILESTTKGD.... RFMSN . VWRIQNFTNLLNTLPHDA...KVQSER. HH IWH I RNF TQF I GSP..... NGTLYSPP. HHIWHIQNFTQI LGGQ.... DTSVYSP HHVWHIRNFTDLLNTSPAGT. AGRIYSPP. F I WRVKNFTQVMENTPNNQ.-.S I FSPP. VWHVRNI TGLLATTPAGR...KAYSPR. HSWRIRDFTKLLATTAPGS - . KIYSPR . KINT........A IYSPR.
40 ..........

$\begin{array}{rrrr}60 & 70 & 80 & 90\end{array}$ FT TYPYGYMLQLEVSLYG IGTWR. GRNL I AGLT ILPGPYDELLEWP. FSNKAFGYALRLDI YLNGKG TWK. GRNMI ACLNVLSGEYDPLLAWP. FYTAKYGYKVCLRI YLNGDGMGK. GTHVSLFFVVMKGDYDALLPWP. FYTGRNGYKMC I RAYLNGDGQGY. NTHLSLFFVIMKGEF DNLLKWP. FYTAKYGYKLCLRLYLNGDGSGK. KTHLSLF IVIMRGEYDALLPWP. FYTAKYGYKLCLRLYLNGDGSGK- KTHLSLF IVIMRGEYDALLPWP
FYTAKYGYKLCLRLYLNGDGTGK. RTHLSLF IVIMRGEYDALLPWP. FYTSKYGYKMCLR IYLNGDGTGR. GTHLSLFF VVMRGHSDALLKWP. FYTSKYGYKMCLR IYLNGDGTGR. GSHLSLFF VVMRGQSDALLKWP. FYTSRYGYKMCLRVYLNGDGTGR-GTHLSLFFVVMKGPNDALLQWP. FYTSRYGYKMCLRI YLNGDGTGR - GTHLSLFF VVMKGPNDALLRWP. FYSSKYGYKMCLRLYLNGDGTGR. GTHLSLFFVVMKGKCDALLKWP. FYSSKYGYKMCLRLYLNGDGTGR. GTHLSLFF VVMRGKCDALLKWP. FYTGYFGYKMCAR I YLNGDGMGK. G THLSLF F VVMRGEYDALLPWP FYTGYFGKMCARVYLNGDGMGK. GTHLSLFFVIMRGEYDALLPWP. - FYTGYFGYKMCARVYLNGDGMGK GTHLSLFFUIMRGEYDALLPWP FYTGYFGYKMCARVYLNGDGMGK. GTHLSLFFVVMRGEYDALLLWP. FYTGYFGYKMCARVYLNGDGMGK. GTHLSLFF VVMRGEYDALLQWP. FYTGYFGYKMCARVYLNGDGMGK. GTHLSLFF VVMRGEYDALLQWP.
FYTSRCGYRLCARAYLNGDGSGR. GSHLSLYFVVMRGEFDSLLQWP. FYTSRCGYRLCARAYLNGDGSGK. GTHLSLYFVVMRGEFDSLLQWP. FYTSRCGYRL CARAYLNGDGSGK. GTHVSLYF VVMRGEFDSLLPWP. AF YTARYGF KVCLRLYLNGDGAGK. GSH I SLFFVIMKGEYDPILSWP. FYTSRSGYKLSVRAYLGGDGSGR. GSHMSLDI TIMRGDFDSFLPWP. FYTSQYGYKLR I KAYLNGRDRGK. GTHLSLYLI IMKGEFDALLEWP. FYTSQYGYKLQASMFLNGNGPGE.NTHVSVYI KVLPGEYDALLKWP. FYTSQYGYKLQASMFLNGNGPGE - GTHVSVYIKVLPGEYDALLKWP. FYTSOYGYKLQASVFLNGNGTGE.GSHISIYIKILPGEYDALLRWP. . FYTHKYGYKL . . FYTHYGYKLQVSAFLNGNGSGE. GTHLSLYIRVLPGAF DNLLEWP. FYTHKYGYKLQVSAFLNGNGSGE.GSYLSVYIRVLPGEYDNLLEWP. FYTHRYGYKLQVSAF LNGNGSGE. GSHLSVYIRVLPGEYDNLLEWP. FYTHRYGYKLQVSAFLNGNGSGE-GSHLS IYIRVLPGEYDNLLEWP FLTSRHGYRLSVSCCLNGDGKAK. SHFMSIFVCINRGEYDALLPWP FMSHRF GYKMMACACLFGDGSSA. GKS I SLYVLLLKGEF DPTLEWP FYTHRNGYAMCVRMYPKGDGSGT. GTHLSMYFNVLKGPVDDNLEWP. FYTHRNGYAMCVRMYPKGDGSGT. GTHLSMYFNVLKGPADDNLEWP. FYTHRNGYAMCVRMYPKGDGSGT - GTHVSMYFNVLKGPADDTLEWP. CYTSPHGYKF CARLNIQPRK.... PHVLSLHVHLMQSENDYHLDWP. AYTSPHGYKFCARINVSPRT. . . KDSIGLHVHLMOSENDYHLEWP. . AYTSPHGYKFCAR N FyT FYTGKPGYKL CMRLHLQLPTAQR CANY I SLF VHTMQGEYDSHLPWP. FYTGRPGYKLCMRLHLQLPTAQRCANYI SLFVHTMQGEYDSHLPWP. FYTGKPGYKLCLRLHIQLPSAQRCANF I SLFVHTMQGEYDSHLPWP. FYTGKPGYKLCLRLHLQLPSAQRCANY I SLFVHTMQGEYDSLLPWP. FYTGRPGYKLCLRLHLQTPSAPRCSNF I SLFVHTMQGEFDSQLSWP. FYTGRPGYKLCLRLHLQSPVAQRCSNF I SLF VHTMQGAYDGLLTWP. FYSHGYGYKMMAVAAPYGDGLAF - REYF SVFVCLMKGEWDD I LEWP. FYNSE - GYGVGVTLYPNGRITSN - SGLLGLTFHLYSGDNDA ILEWPV FYNSE - GYGFGVTLYPNSR - -ES - SGYLRLAFHVCSGENDA I LEWPV FYSPE. GYAYG ISLYPQSNSNG....YTRVAFHLCSGENDAVLEWPA FYSPE. GYGYGVRLVPLSNYTDYTGNYTGLYFHLASGENDAVLQWPA CFTSPEGYGYAVS I YPHGQESSPYVNYTGI SF HMCSGEDDDVMEWPA CFTSPEGYGYAVS I YPHGQESSPYVNYTG ISFHMCSGEDDDVMEWPA
FYNSE.GYAYG INVYPNGRVNSS. KEFVGITFNLFGGENDAVLEWPA FYSSK.GYAFQ I YLNLAHVT....... NAG IYFHLI SGANDDQLQWPC FYSSK. GYAFQ I YMDLRY...... ST NVVG I YFHL I SGANDDQLQWPC FYSST - GYAFQVGLYVNG. TTDN. PFNLA IYLHL ISGANDDQLQWPC FKSKE- GYTF QMQLYPNG. TDKY. PGQLGAFAHLVAREGDTGQEWPC FLSST - GYSF QVGVYLNG - VSSR - PGYMAVYLHLT SGPNDHKLRWPC LLSPD. GYSFQIGLYINGLKDS. PDKMA IYLHLTSGPHDDNLQWPC

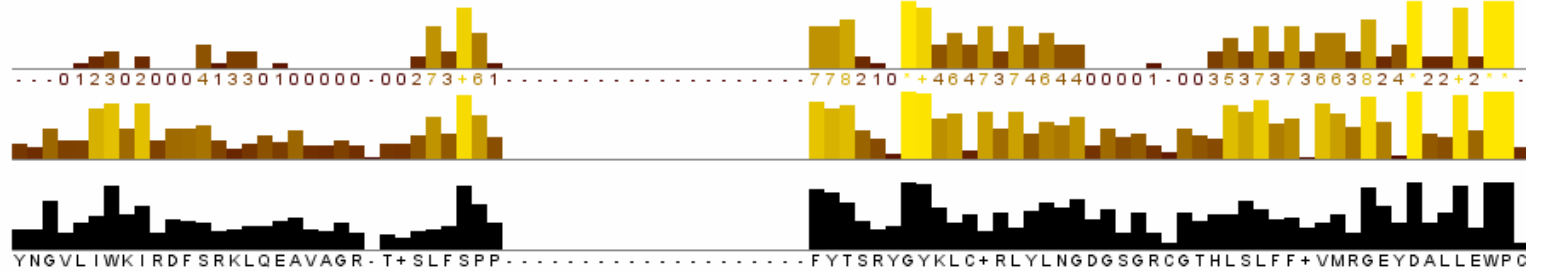




\section{Fig. 8 (cont)}

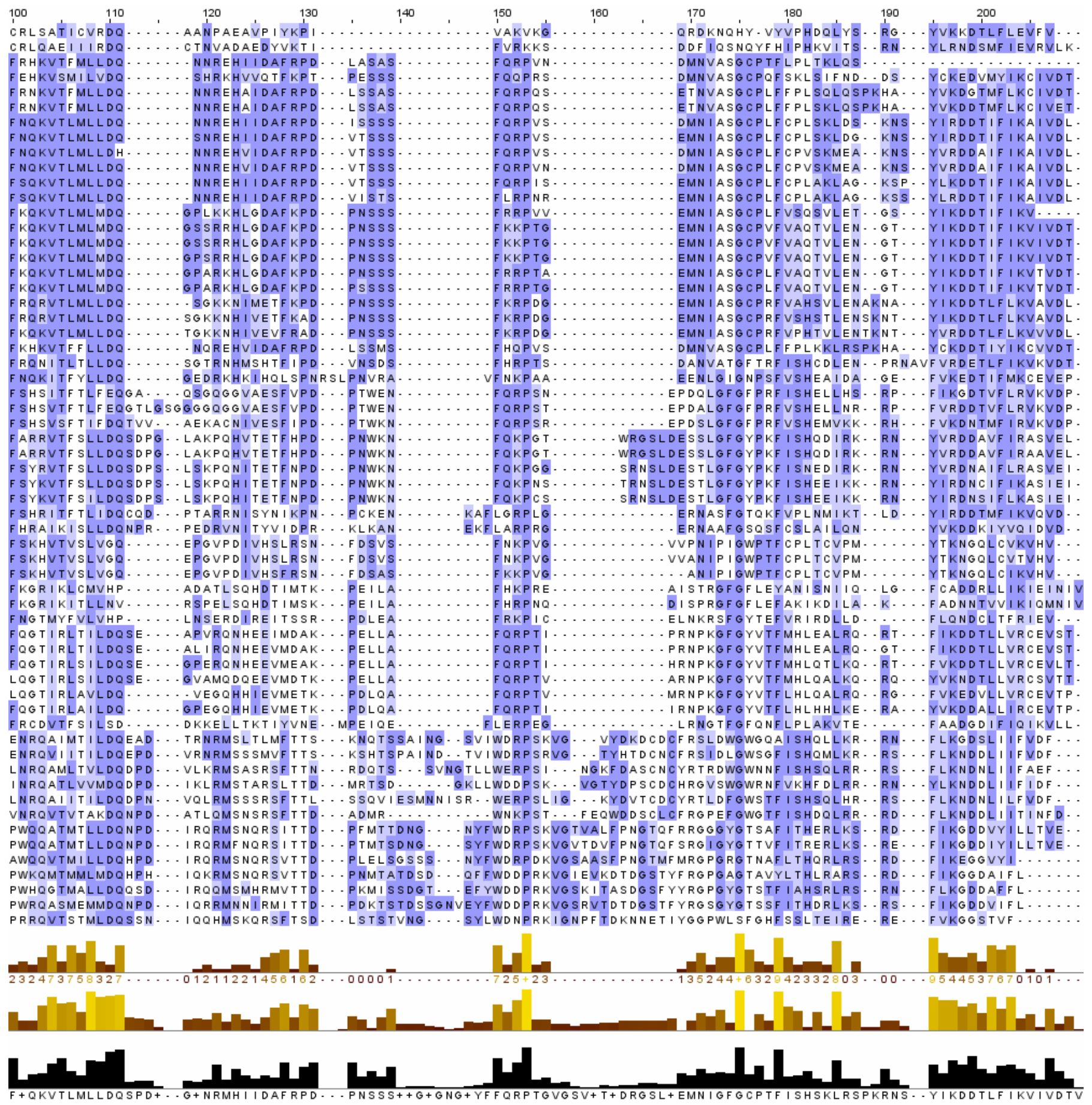

